\title{
- Influence of the Eurasian Spring Snowmelt on Summer Land Surface Warming over Northeast Asia and Its Associated Mechanism
}

\author{
Yue Sun, ${ }^{\mathrm{a}, \mathrm{b}}$ Haishan Chen, ${ }^{\mathrm{a}, \mathrm{b}, \mathrm{c}}$ Siguang Zhu, ${ }^{\mathrm{a}, \mathrm{b}}$ Jie Zhang, ${ }^{\mathrm{a}, \mathrm{b}}$ AND JiAngfeng Wei ${ }^{\mathrm{a}, \mathrm{b}}$ \\ ${ }^{a}$ Key Laboratory of Meteorological Disaster, Ministry of Education/International Joint Research Laboratory of Climate and \\ Environment Change/Collaborative Innovation Center on Forecast and Evaluation of Meteorological Disasters, \\ Nanjing University of Information Science and Technology, Nanjing, China \\ ${ }^{\mathrm{b}}$ School of Atmospheric Sciences, Nanjing University of Information Science and Technology, Nanjing, China \\ ${ }^{\mathrm{c}}$ NUIST-University of Reading International Research Institute, Nanjing University of Information \\ Science and Technology, Nanjing, China
}

(Manuscript received 28 September 2020, in final form 9 March 2021)

\begin{abstract}
Under the background of global warming, the Eurasian warming features evident spatial heterogeneity, and Northeast Asia (NEA) is one of the regions with the most significant summer warming. Based on reanalysis data and the CESM1.2.2 model, we investigated the possible impacts of spring Eurasian snowmelt on recent NEA summer warming and the relevant mechanisms. Results show that increased (decreased) spring snowmelt over eastern Europe to western Siberia (EEWS) is closely linked to NEA summer warming (cooling). Increased spring snowmelt can wet the soil, weakening surface sensible heating to the atmosphere and cooling the atmosphere. The persistent anomalous soil moisture and surface sensible heat induce geopotential height decrease over EEWS and strengthen the eastward-propagating wave train. Furthermore, positive geopotential height anomalies appear in downstream NEA in summer via the adjustment of the atmospheric circulation. Controlled by the anomalous high pressure system, the west part of NEA is affected by the southerly warm advection, while the east is affected by adiabatic warming induced by the dominant descending motion. Meanwhile, decreased cloud and increased incident solar radiation over NEA favor summer land surface warming. Model results suggest that CESM1.2.2 can basically reproduce the positive correlation between NEA summer land surface temperature and EEWS spring snowmelt. With the positive spring snowmelt forcing, the simulated positive soil moisture and negative sensible heat anomalies persist from spring to summer over EEWS. Consequently, negative geopotential height anomalies appear over the snowmelt region while positive anomalies occur around Lake Baikal, resulting in evident NEA land surface warming.
\end{abstract}

KEYWORDS: Land surface; Atmosphere-land interaction; Snowmelt/icemelt; Surface temperature; Climate variability

\section{Introduction}

Under the background of global warming, the land generally exhibits stronger warming than the ocean. The land surface temperature (LST) over Eurasia has been significantly increasing (Xu et al. 2011; Chen and Lu 2014a; Kamae et al. 2014; Dong et al. 2016, 2017). Observational analysis shows that summer warming over Eurasia presents evident spatial heterogeneity that features a zonal tripole pattern, and Northeast Asia (NEA; i.e., around Lake Baikal) experiences the most robust warming (Ito et al. 2013; Chen et al. 2016; Dong et al. 2016; Hong et al. 2017; Sato and Nakamura 2019). Land surface thermal conditions are usually closely linked to the climate, and the existing studies suggest that summer land thermal anomalies significantly impact the East Asian summer monsoon (EASM) and summer air temperature and precipitation in China (Xu et al. 2011; Zhu et al. 2012; Chen and Lu 2014a; Chen et al. 2017, 2019). Therefore, it is necessary to better understand the causes of the land

¿ Denotes content that is immediately available upon publication as open access.

Corresponding author: Haishan Chen, haishan@nuist.edu.cn surface thermal anomalies over NEA and the related climatic effects.

The possible causes of the recent NEA summer warming have been widely investigated. Studies emphasized the impacts of anomalous atmospheric circulation, especially the atmospheric teleconnection patterns, on NEA climate. It has been noted that the Silk Road pattern (SRP) along the subtropical jet waveguide (Lu et al. 2002; Kosaka et al. 2012; Hong and Lu 2016), the British-Baikal Corridor (BBC) pattern along the polar front jet (Hsu and Lin 1992; Terao 1998; Iwao and Takahashi 2008; P. Q. Xu et al. 2019), and the East Asia-Pacific (EAP) teleconnection pattern (Hirota and Takahashi 2012; Chen and Lu 2014b; Chen et al. 2016) can significantly affect the NEA summer temperature. The abnormal local circulation associated with the activity centers of these atmospheric teleconnection patterns usually influence LST directly (Schubert et al. 2011, 2014). Other studies focused on the role of the external forcing, such as sea surface temperature (SST), sea ice concentration (SIC), and the anthropogenic forcing, in recent land surface warming (Sutton et al. 2007; Ito et al. 2013; Kamae et al. 2014; Gao et al. 2015; Dong et al. 2016; He et al. 2018; Li et al. 2018; Sun et al. 2019b). For example, Hong et al. (2017) pointed out that the Atlantic multidecadal oscillation (AMO) amplifies the warming over Europe-West Asia and NEA by modulating the SRP. The anthropogenic forcing also affects 
LST through the so-called fast response, which is believed to be independent from the impacts of SST (Andrews et al. 2012; Kamae and Watanabe 2013). In addition, the local landatmosphere coupling (Orth and Seneviratne 2017; Sato and Nakamura 2019; Chen et al. 2020), the dynamics and thermodynamics of the atmosphere (Sun et al. 2019a; Wang et al. 2019), and the cloud-radiation interaction (Dai et al. 1999; Betts et al. 2014; Ye et al. 2015) all contribute to the land surface thermal anomalies.

Most studies emphasized the contributions of the large-scale atmospheric circulation, SST, SIC, and human activity to the land surface warming. However, the role of the land surface process itself, especially of that in the previous season, has not been well understood. As one key land surface factor and one important component of the cryosphere, snow covers most parts of the Eurasian continent in spring and winter, and strongly interacts with the atmosphere. Since Blanford (1884) found a negative correlation between the Himalayan winter snow and the Indian summer monsoon, snow cover has been long recognized as an important factor affecting the climate, and its climatic effects has been widely studied. Previous works (Ge and Gong 2009; Zuo et al. 2011, 2012) revealed that snow cover bears a close relationship with contemporary climate. More importantly, studies suggest that the lagged climatic effect of snow cover can favor the climate prediction (Chen and Song 2000; Wu and Kirtman 2007; Zhang et al. 2008; Mu and Zhou 2010, 2012; Shen et al. 2020). For example, Yim et al. (2010) found that the dipole pattern of snow-cover anomalies is associated with the summer rainfall in the East Asian monsoon area, providing an important reference for the East Asian summer rainfall prediction. Xu et al. (2018) reported that the abnormal Eurasian snow cover in October can trigger the Rossby wave train via the stratosphere-troposphere interaction, and further influence the typical "warm Arctic-cool Eurasia" air temperature pattern in January.

Snow cover has been suggested to be an important predictor for climate prediction, and the relevant mechanisms deserve better understanding. Changes in snow cover can alter the radiation budget, heat balance, and water balance at the underlying surface, and further affect the atmosphere via the albedo and hydrological effects (Cohen and Rind 1991; Groisman et al. 1994). The local effect of snow cover can trigger a remote response of the atmospheric general circulation and further affect the regional and even global climate. In wintertime, the more evident snow-albedo effect significantly reduces the absorption of solar radiation by the land surface and weakens the heating effect (Souma and Wang 2010; Wu et al. 2014a; Ye et al. 2015). In spring, the snowhydrological effect is more prominent. Snowmelt directly affects the soil water, which further adjusts the thermal states of the land surface and the thermal forcing to the atmosphere. Due to the persistence of soil moisture anomalies, the snowhydrological effect usually produces evident lagged effects on the following summer climate (Barnett et al. 1989; Cohen and Rind 1991; Xu and Dirmeyer 2011, 2013; Matsumura and Yamazaki 2012). Spring snow cover usually bears a close relationship with the monsoon, rainfall, and air temperature in the following summer, and its lagged climatic effects have been well recognized (Zhao et al. 2007; Halder and Dirmeyer 2017; Zhang et al. 2017; Ye and Lau 2019; Shen et al. 2020; Xu et al. 2021). Studies show that the snow-hydrological effect can persist for months (Xu and Dirmeyer 2013) and that soil moisture acts as a bridge between snow cover and the climate in the following season (Yasunari et al. 1991; Yim et al. 2010; Wu et al. 2014b). Yim et al. (2010) disclosed a close linkage between spring snow cover in the Tibetan Plateau and the EASM rainfall, and highlighted the bond role of the soil moisture in May and June in the linkage. Xu and Dirmeyer (2011) suggested that the strongest snow-atmosphere coupling happens during snowmelt. After snowmelt, the signal of abnormal snow cover can be retained by soil moisture and the snow-atmosphere coupling strength is maintained due to the snow-hydrological effect.

More recently, the rapid summer land surface warming over NEA has caused mounting concern. The possible impacts of land surface factors in the previous season, especially of snow cover, have not been well explored until now. In addition, studies relevant to the snow climatic effect commonly used seasonal average to reflect the variation of snow cover. In fact, the lagged impact of snow cover mainly depends on its hydrological effect. Spring snow cover exhibits evident intraseasonal variation, and snowmelt can better represent the variation of snow amount rather than the mean state of snow cover. Using seasonal averages, it is hard to reflect the snow-hydrological effect and describe the lagged effect on the climate in the following summer directly and accurately. Snowmelt plays an important role in determining the hydrological cycle, and can directly change the local soil moisture, which then lead to the climate anomalies by influencing the surface thermal conditions (Groisman et al. 1994; Souma and Wang 2010; Ye and Lau 2019). Based on previous studies (Dey and Bhanu Kumar 1982; Chen et al. 2013; Zhang et al. 2017), we defined spring snowmelt as the difference in snow water equivalent (SWE) between March and May to reflect the variation of spring snow amount, and further explored the relationship between spring snowmelt and NEA summer land surface warming. Zhang et al. (2017) recently found that the west-east dipole mode of the spring snow decrement is associated with the third EOF mode of East Asia summer rainfall through triggering an anomalous midlatitude Eurasian wave train. However, the possible impacts of Eurasian spring snowmelt on NEA summer LST and the associated physical mechanisms deserve further investigation.

Therefore, this study aimed to explore the possible influence of Eurasian spring snowmelt on NEA summer land surface warming as well as the relevant pathway and mechanisms. SWE was selected to better reflect the snow-hydrological effect and snowmelt. Our study will benefit comprehensive understanding and provide useful information for prediction of land surface warming and climate in summer. Section 2 describes the data, methods, model, and numerical experiments. The possible linkage between spring snowmelt and summer LST is presented in section 3. Section 4 explores the relevant mechanisms and section 5 discusses the numerical results. Discussion and conclusions are given in sections 6 and 7 , respectively. 


\section{Data, methods, and model}

\section{a. Data}

The datasets used include the following: 1) The monthly gridded SWE data with a horizontal resolution of $25 \mathrm{~km} \times$ $25 \mathrm{~km}$ provided by the Finnish Meteorological Institute (FMI) (Takala et al. 2011), whose detailed information is available via http://www.globsnow.info/. Based on the combination of satellite-based microwave radiometer data and ground-based weather station data, this snow product well represents the real snow conditions (B. Xu et al. 2019). The original data were converted to regular $1^{\circ}$ latitude-longitude grid data for our analysis. 2) ERA-Interim monthly mean surface temperature, 2-m temperature, soil moisture, and surface heat flux reanalysis data with a horizontal resolution of $1^{\circ} \times 1^{\circ}$ (Dee et al. 2011). In particular, the soil moisture data have four layers that are about $0-7,7-28,28-100$, and 100-289 cm in depth. The 0-7-cm layer was used in this study. 3) Global Land Data Assimilation System (GLDAS, v2.0) (Rodell et al. 2004) and ERA5-Land (available at https://doi.org/10.24381/cds.68d2bb30) monthly soil moisture and surface heat flux reanalysis data, which are based on offline land surface model. 4) The monthly mean atmospheric fields from the National Centers for Environmental Prediction (NCEP)-National Center for Atmospheric Research (NCAR) Reanalysis (Kalnay et al. 1996). 5) The Oceanic Niño
Index (ONI) from the National Oceanic and Atmospheric Administration (NOAA) Climate Prediction Center (CPC), which is based on the 3-month running mean of ERSST.v5 SST anomalies in the Niño-3.4 region $\left(5^{\circ} \mathrm{N}-5^{\circ} \mathrm{S}, 120^{\circ}-170^{\circ} \mathrm{W}\right)$, and can indicate ENSO signal (available online at https:// origin.cpc.ncep.noaa.gov/products/analysis_monitoring/ensostuff/ ONI_v5.php). 6) Cloud-cover data from the NOAA Advanced Very High Resolution Radiometer (AVHRR) PATHFINDER Atmospheres Extended (PATMOS-x) cloud fraction datasets (Heidinger et al. 2012). The time period in this study is from 1981 to 2014, which is the common range of all these datasets. Besides, due to a significant warming trend in NEA surface temperature, the linear trends were removed from all variables before analysis to avoid the effect of long-term tendency on correlation.

\section{b. Methods}

The EOF analysis was used to acquire the dominant modes of the variations in both summer LST and spring snowmelt. Additionally, this study employed statistical methods such as correlation, composite, and regression analysis. To represent the Rossby wave propagation, the three-dimensional (3D) wave activity flux (WAF) was also calculated according to Takaya and Nakamura (2001) as follows:

$$
\mathbf{W}=\frac{p \cos \phi}{2|\mathbf{U}|}\left\{\begin{array}{c}
\frac{U}{a^{2} \cos ^{2} \phi}\left[\left(\frac{\partial \psi^{\prime}}{\partial \lambda}\right)^{2}-\psi^{\prime} \frac{\partial^{2} \psi^{\prime}}{\partial \lambda^{2}}\right]+\frac{V}{a^{2} \cos \phi}\left[\frac{\partial \psi^{\prime}}{\partial \lambda} \frac{\partial \psi^{\prime}}{\partial \phi}-\psi^{\prime} \frac{\partial^{2} \psi^{\prime}}{\partial \lambda \partial \phi}\right] \\
\frac{U}{a^{2} \cos \phi}\left[\frac{\partial \psi^{\prime}}{\partial \lambda} \frac{\partial \psi^{\prime}}{\partial \phi}-\psi^{\prime} \frac{\partial^{2} \psi^{\prime}}{\partial \lambda \partial \phi}\right]+\frac{V}{a^{2}}\left[\left(\frac{\partial \psi^{\prime}}{\partial \phi}\right)^{2}-\psi^{\prime} \frac{\partial^{2} \psi^{\prime}}{\partial \phi^{2}}\right] \\
\frac{f_{0}^{2}}{N^{2}}\left\{\frac{U}{a \cos \phi}\left[\frac{\partial \psi^{\prime}}{\partial \lambda} \frac{\partial \psi^{\prime}}{\partial z}-\psi^{\prime} \frac{\partial^{2} \psi^{\prime}}{\partial \lambda \partial z}\right]+\frac{V}{a}\left[\frac{\partial \psi^{\prime}}{\partial \phi} \frac{\partial \psi^{\prime}}{\partial z}-\psi^{\prime} \frac{\partial^{2} \psi^{\prime}}{\partial \phi \partial z}\right]\right\}
\end{array}\right\}+\mathbf{C}_{U^{\prime} M,}
$$

in which $p=($ pressure $/ 1000 \mathrm{hPa})$; the basic flow $\mathbf{U}=(U, V, 0)^{\mathrm{T}}$, $U$ is the zonal wind component, $V$ is the meridional wind component; $a$ is the radius of Earth; $\phi$ and $\lambda$ are the latitude and longitude, respectively; $\psi^{\prime}$ is the perturbation streamfunction; $z=-H \operatorname{lnp}$, where $H$ is a constant scale height; $N^{2}$ is the buoyancy frequency squared; $\mathbf{C}_{U}$ represents the phase propagation in the direction of $\mathbf{U}$; and $M$ is pseudomomentum.

\section{c. Model description and experimental design}

We conducted numerical experiments with the Community Earth System Model 1.2.2 (CESM1.2.2) to verify the results of statistical analysis. CESM, a coupled climate model for simulation of Earth's climate system, is composed of separate modules including atmosphere, ocean, land, land ice, and sea ice, plus one central coupler. The atmosphere module, Community Atmospheric Model version 5 (CAM5.0), and the land module, Community Land Model version 4.5 (CLM4.5), were used in our coupling tests, and forced by climatological SST.
To validate the impact of spring snowmelt on NEA summer LST, corresponding experiments were performed. We used the climatological SST to integrate forward for 60 years continuously, and the first 10 years were for spinup. The output data on 1 January of the last 50 years were treated as 50 initial fields for control (CTL) and sensitivity (SNO) experiments. Then, these two sets of experiments integrated for 8 months from 1 January to 31 August, each with 50 ensemble members. To depict characteristics of abnormal spring snowmelt better, snowfall rate modification was adopted in the SNO experiments referring to Barnett et al. (1989). Besides, since snowmelt is dominated by net solar radiation at the surface (Molotch et al. 2004), the snow albedo change was used to characterize snow reduction in the later period. Concretely, we increased the snowfall rate by $20 \%$ in January and February, and reduced it in April in the key snowmelt region. Meanwhile, the snow albedo in April and May was decreased by $20 \%$; in this way, the simulation results would be close to the real snow conditions. The experimental design is summarized in Table 1 . The 
TABLE 1. Experimental design used with CESM1.2.2.

\begin{tabular}{lc}
\hline \hline Expt & \multicolumn{1}{c}{ Description } \\
\hline CTL & \multicolumn{1}{c}{ Control run } \\
SNO & $\begin{array}{c}\text { Snowfall rate }+20 \% \text { in January and February, snow } \\
\text { albedo }-20 \% \text { in April and May in snowmelt key } \\
\text { region }\end{array}$ \\
\hline
\end{tabular}

ensemble mean difference between the SNO and CTL runs was calculated to demonstrate the snowmelt effects.

\section{Relationship between Eurasian spring snowmelt and NEA summer land surface warming}

To explore the possible relationship between NEA summer land surface thermal conditions and Eurasian spring snowmelt, an EOF analysis of detrended summer LST in NEA $\left(35^{\circ}-60^{\circ} \mathrm{N}\right.$, $90^{\circ}-130^{\circ} \mathrm{E}$ ) was carried out first. The first principal component (PC1), accounting for $34.3 \%$ of the total variance, is significantly distinguished from other modes according to the criterion of North et al. (1982). The spatial pattern of the first mode (EOF1) displays positive anomalies over the whole region, with two maximum centers in the southwest and southeast of
Lake Baikal, respectively (Fig. 1a). The corresponding time series shows obvious interannual variations (Fig. 1b). We also conducted an EOF analysis on Eurasian LST, which shows that there are two rapid warming centers over Europe and NEA, and the center in NEA is consistent with that in Fig. 1a. Figure 1c presents the correlation distribution of NEA summer LST with the time coefficients of PC1. A significant positive correlation exists throughout NEA, with the center located in the south of Lake Baikal. Compared to Fig. 1a, the correlation center is more northerly, but the general distributions are consistent. Subsequently, we defined the NEA summer LST index LSTI as the time series of PC1 for the following study.

Figure 2 presents the monthly climatology of SWE. It can be found that SWE reaches a peak in March, and gradually reduces in April and May. Referring to previous studies (Dey and Bhanu Kumar 1982; Chen et al. 2013; Zhang et al. 2017), we defined the difference in SWE (DSWE) between March and May as the spring snowmelt amount and then analyzed the relationship between Eurasian spring snowmelt and NEA summer LST. Figure 3a shows large-scale significant positive correlation of spring snowmelt with LSTI in eastern Europewestern Siberia (EEWS) and relatively weak positive signals around Lake Baikal. Also, a weak negative correlation exists in southern eastern Europe and central Siberia. We chose EEWS
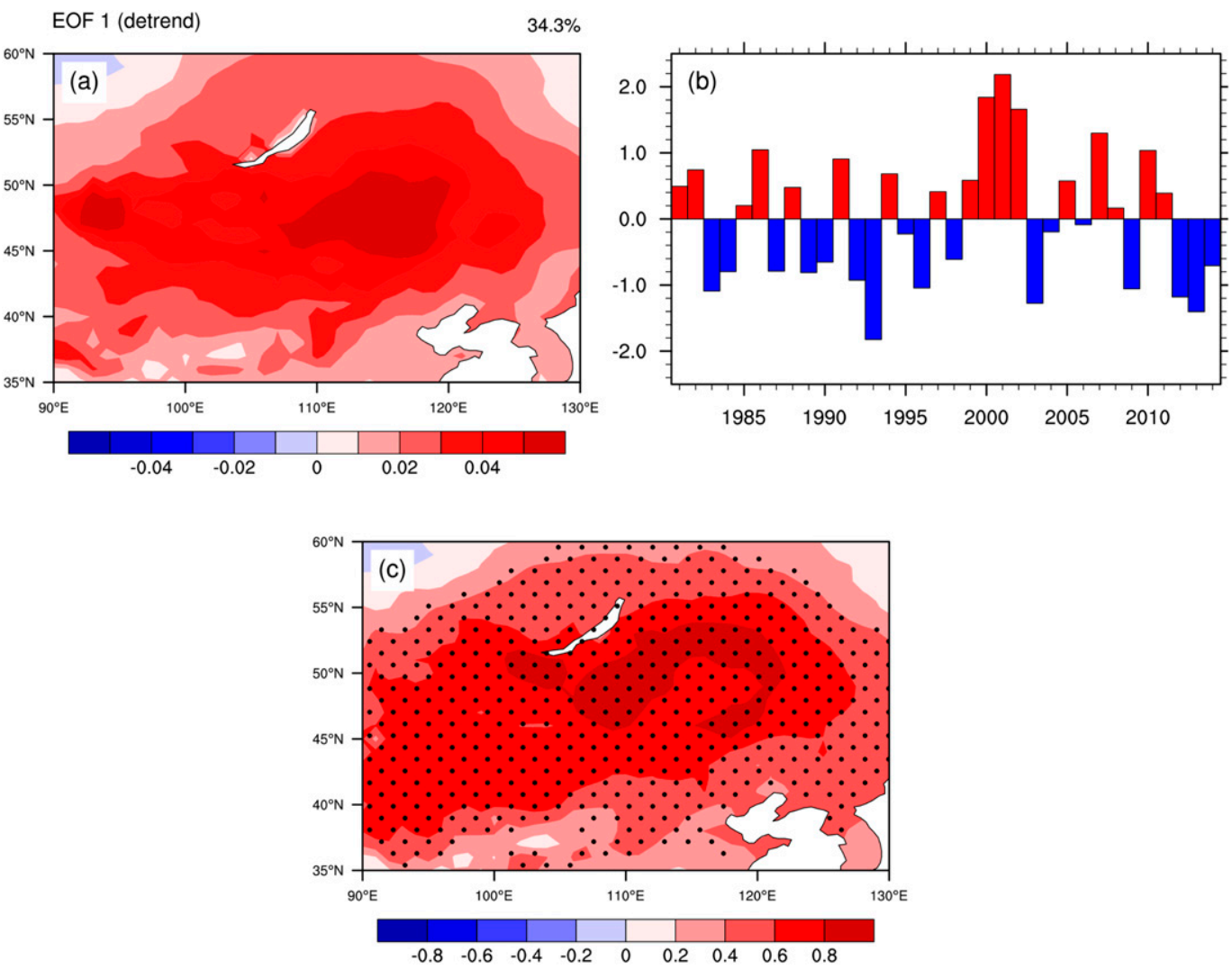

FIG. 1. (a) Spatial pattern of the first EOF (EOF1) mode and (b) the corresponding standardized time series of first principal component (PC1) of detrended summer LST over NEA for the period 1981-2014, and (c) the correlation coefficient field of summer NEA LST with the time coefficients of PC1. The dotted regions denote that the correlation coefficient is significant at the $95 \%$ confidence level according to the Student's $t$ test. 


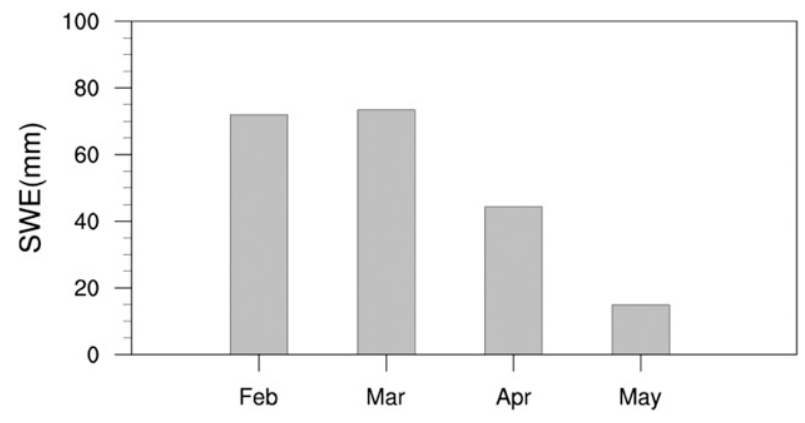

FIG. 2. Eurasian climatology of monthly SWE (mm) north of $50^{\circ} \mathrm{N}$ in the snowmelt season.

$\left(55^{\circ}-70^{\circ} \mathrm{N}, 50^{\circ}-80^{\circ} \mathrm{E}\right)$ as the key region of spring snowmelt, and defined the snowmelt index DSWEI as the area-averaged snowmelt in EEWS (Fig. 3c). Figure 3b shows the spatial distribution field of the second mode (EOF2) of Eurasian spring snowmelt, which explains about $16.4 \%$ of the total variance. This spatial pattern is similar to Fig. 3a, except some opposite signals near Lake Baikal. The corresponding time series of this mode is also consistent with DSWEI, and the correlation coefficient is 0.88 .

To further confirm that NEA summer LST is relevant to EEWS spring snowmelt, regression maps of the summer LST against DSWEI are given in Fig. 4a. Consistent with Fig. 1a, large-scale positive anomalies exist around Lake Baikal, with two centers in its southwest and southeast. Figure $4 \mathrm{c}$ shows a coherent variation between LSTI and DSWEI. The correlation coefficient is 0.54 , exceeding the $99 \%$ confidence level, which indicates that EEWS spring snowmelt explains about $30 \%$ of the NEA summer LST variance. Considering that the tropical ocean signal has an important influence on East Asian climate, the independence of the relationship between EEWS snowmelt and NEA LST should also be examined. Figure $4 \mathrm{~b}$ depicts regressed NEA summer LST onto DSWEI with the ENSO signal removed through the linear regression method, which is similar to the regression pattern before removal of the signal. Furthermore, the partial correlation between DSWEI and LSTI with the linear parts related to Niño-3.4 index excluded is 0.57, close to the correlation between DSWEI and LSTI, which manifests the relationship between EEWS spring snowmelt and NEA summer LST is independent of ENSO. The above results suggest that NEA summer LST is closely related to EEWS spring snowmelt. Growing summer LST over NEA corresponds to increased EEWS spring snowmelt, and vice versa. However, with a certain span of time and space between the two, how does spring snowmelt exert a nonlocal impact on the later climate? The possible physical mechanisms need further exploration.

\section{Possible influence pathway}

To elucidate the effects of EEWS spring snowmelt on NEA summer LST, we selected high and low snowmelt years based on DSWEI with a threshold of 1.0 standard deviation, and analyzed the composite difference fields of related land surface variables. According to previous studies (Barnett et al. 1989; Yasunari et al. 1991; Matsumura and Yamazaki 2012; Halder and Dirmeyer 2017; Ye and Lau 2019), melting snow can induce soil moisture changes and then change land surface
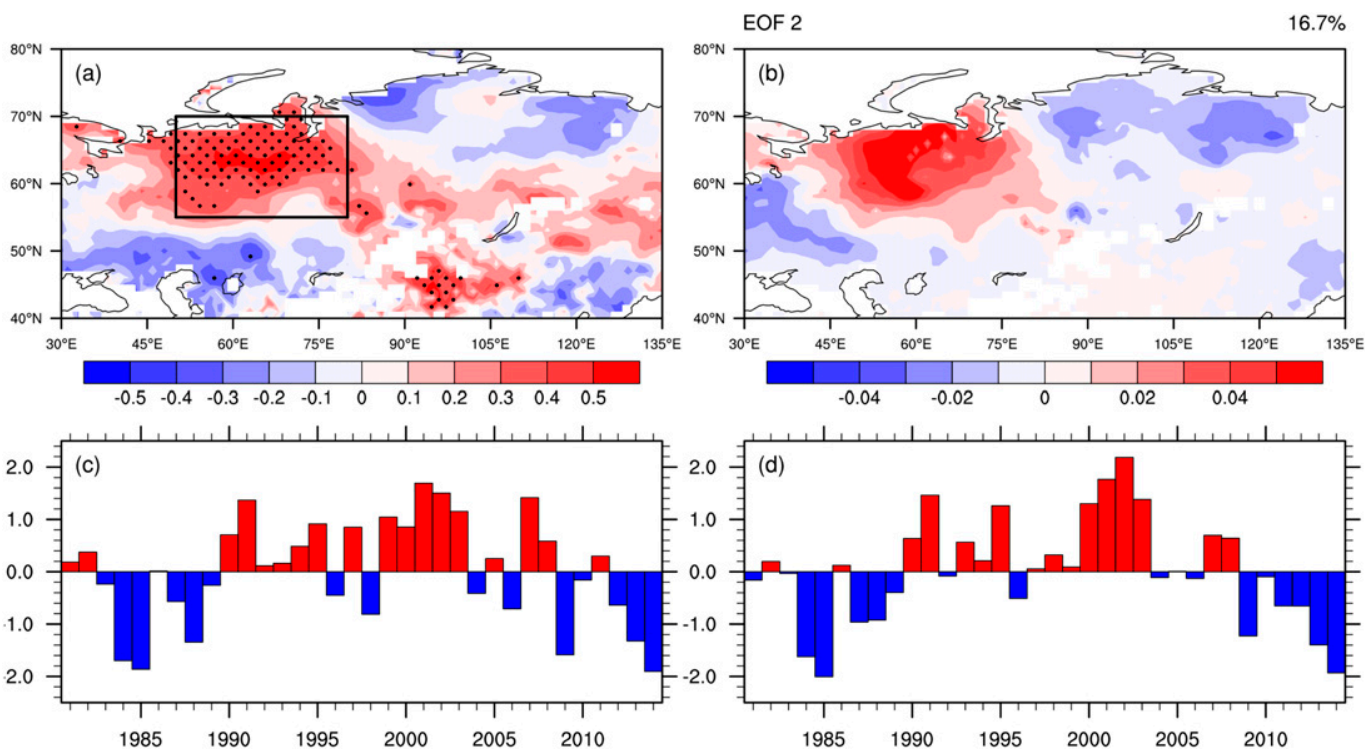

FIG. 3. (a) Correlation coefficient field of DSWE with LSTI, (b) spatial pattern of the second EOF (EOF2) mode and (d) the corresponding standardized time series of second principal component (PC2) of DSWE over Eurasia during 1981-2014. (c) The area-averaged time series of DSWE in EEWS. The black box in (a) denotes EEWS (55 $70^{\circ} \mathrm{N}, 50^{\circ}-80^{\circ} \mathrm{E}$ ), and the dotted regions represent that the correlation coefficient is significant at the $95 \%$ confidence level based on the Student's $t$ test. 

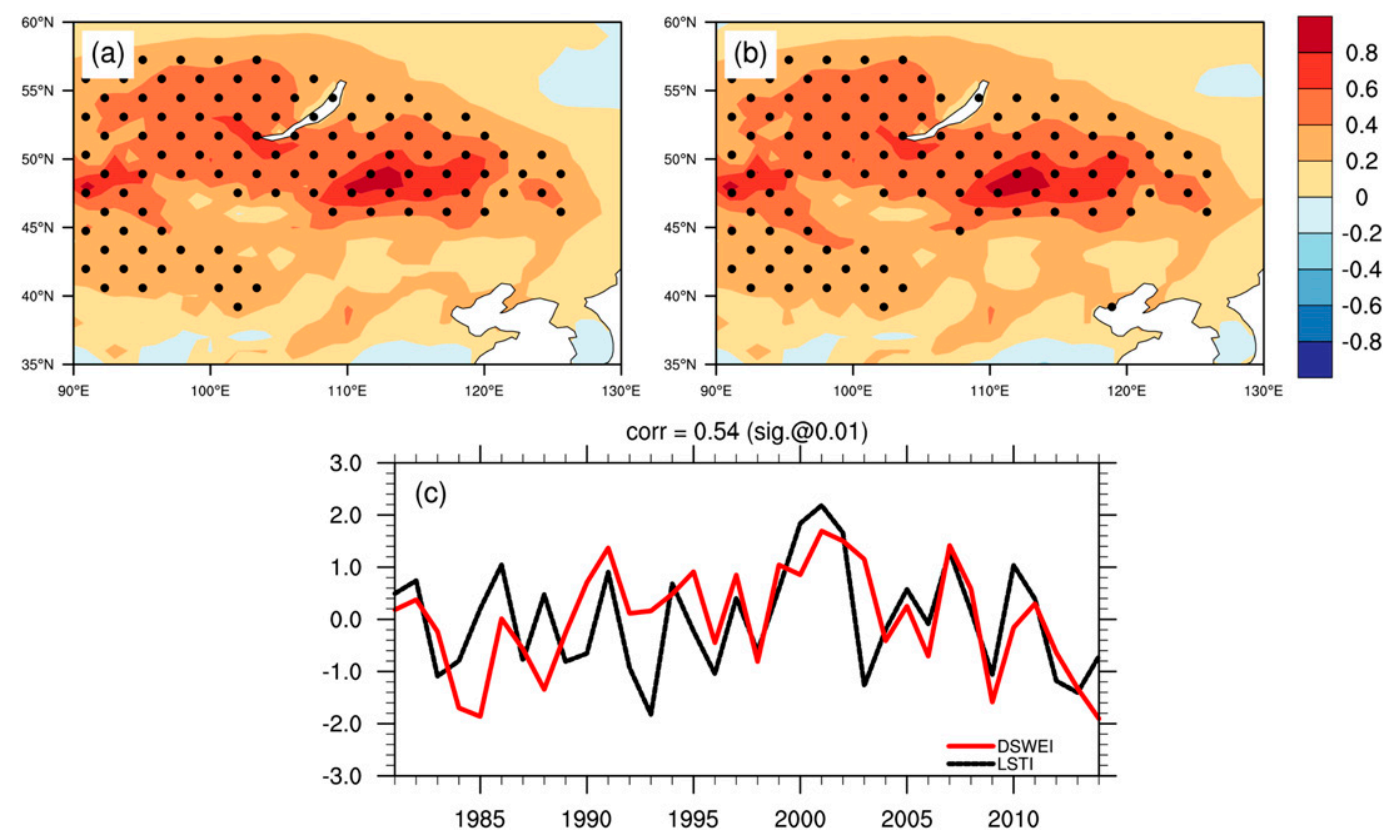

FIG. 4. Summer (JJA) LST (K) regressed onto DSWEI (a) before and (b) after removal of ENSO signal. (c) Time series of LSTI (black line) and DSWEI (red line) and the correlation coefficient. the dotted regions in (a) and (b) indicate the regression coefficients significant at the $95 \%$ confidence level based on the Student's $t$ test.

thermal conditions, thus affecting the local surface diabatic heating to the atmosphere above. The soil moisture persistence ultimately leads to delayed climate effects. The composite difference fields of soil moisture in late spring-early summer [May-June (MJ)] and summer [June-August (JJA)] are displayed in Fig. 5. By the end of spring snow thawing (Fig. 5a), extensive significant positive soil moisture anomalies emerge near the Ural Mountains, corresponding to excessive snowmelt there. Some negative anomalies appear in the northern EEWS region, possibly resulting from incomplete snowmelt at this time. In summer (Fig. 5b), with the Eurasian snow almost melted, positive signals begin to appear in northern EEWS, and the soil moisture is abnormally high in the entire EEWS. This correspondence between snowmelt and soil moisture is a manifestation of the snow-hydrological effect to some extent. The soil moisture anomalies may result from spring snowmelt. Increased EEWS spring snowmelt may induce wet soil locally, and vice versa (Groisman et al. 1994; Souma and Wang 2010; Ye and Lau 2019). Overall, the distribution features in summer resemble those in late spring, with positive anomalies of soil moisture over EEWS. Figure 5c presents the area-averaged time series of EEWS soil moisture in MJ and JJA, which reflect the consistent variations of soil moisture in late spring and summer. In addition, through quantifying the persistence of soil moisture, we found that the soil moisture over EEWS can persist from late spring to summer, which is also in accord with previous studies (Shinoda 2001; Zhang et al. 2017).

Significant soil moisture anomalies also exist outside EEWS. This kind of signal corresponds to EOF2 of Eurasian spring snowmelt shown in Fig. 3b, despite some exceptions in central Siberia. It was found that the spring snowmelt amount in central Siberia is relatively low but that significant positive signals of soil moisture emerging there may be due to the snowmelt process in this area. Observation shows that the Eurasian snow cover gradually melts from southwest to northeast as the season progresses. In central Siberia, snow melts later than in EEWS. Some snow is retained in late spring, and then continues to melt in summer (Wu and Chen 2016; Halder and Dirmeyer 2017). Studies have revealed a negative correlation between snowmelt during spring and summer in central Siberia. With less spring snowmelt, more snow remains, causing increased summer snowmelt (Mu and Zhou 2012; Chen et al. 2013). Therefore, the positive soil moisture anomalies in central Siberia are probably due to later snowmelt and more summer snowmelt. In addition, it was found that the soil moisture anomalies over EEWS and NEA are opposite, which is different from Dong et al. (2016, their Fig. 14b), with the consistent decreases in soil moisture over Europe and NEA caused by changes in aerosols. This difference may be due to the two different forcing, and the details need further study.

The soil moisture change affects the land surface heat balance, thereby modulating diabatic heating to the atmosphere (Seneviratne et al. 2010; Koster et al. 2016). Figure 6 depicts the land-atmosphere temperature difference and upward surface sensible heat flux fields composited by high and low DSWEI years. Significant negative anomalies of land-atmosphere temperature difference occur over EEWS in MJ, and extend eastward to parts of central Siberia, while weak positive anomalies exist near Lake Baikal (Fig. 6a). In JJA, the area of negative land-atmosphere temperature difference anomalies in central Siberia is larger (Fig. 6c), which corresponds to the distribution of soil moisture. This correspondence may indicate that the 

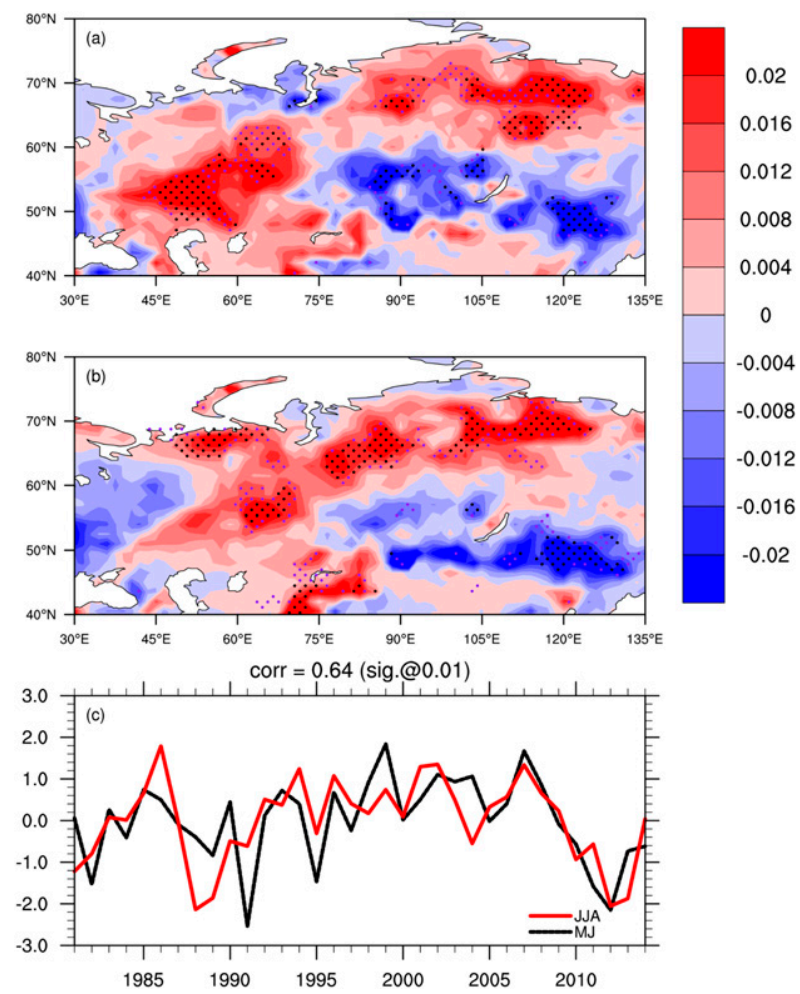

FIG. 5. Composite difference of 0-7-cm soil moisture $\left(\mathrm{m}^{3} \mathrm{~m}^{-3}\right)$ between high and low DSWEI years in (a) MJ and (b) JJA, and (c) the corresponding area-averaged time series over EEWS in MJ (black line) and JJA (red line). The black (purple) dotted areas exceed the $95 \%$ (90\%) confidence level based on the Student's $t$ test.

negative soil moisture anomalies can affect the decrease of local surface temperature, and then lead to negative anomalies of land-atmosphere temperature difference. Furthermore, sensible heating from the land also changes with the altering landatmosphere temperature difference. As shown in Fig. 6b, significant negative anomalies are observed over EEWS and central Siberia, but the intensity is relatively small in the latter area. In summer, the distribution is similar to that in MJ (Fig. 6d), which implies a continuous anomalous cooling of the lower troposphere from the land surface over EEWS and central Siberia. By comparing Figs. 5 and 6, it can be found that the distributions of land-atmosphere temperature difference and sensible heat correspond well to that of soil moisture, especially in EEWS. We also checked the results of regression analysis in these surface variables, which are consistent with that of composite analysis. Besides, the soil moisture and surface sensible heat flux data from ERA5-Land and GLDAS-2.0 datasets are also used to confirm these surface thermal anomalies, and the main characteristics of land surface variables anomalies associated with EEWS spring snowmelt still exist (figures not shown). The above analysis suggests that spring snowmelt anomalies may change the surface thermal conditions through local soil moisture anomalies induced by the snow-hydrological effect, which cause changes in the land-atmosphere temperature difference, and thus affect the sensible heating from the land to the atmosphere above. The anomalous sensible heat flux further causes the change in the atmospheric thickness between the lower and middle troposphere (figure not shown), and thus lead to geopotential height anomalies in the middle troposphere. And the persistent soil moisture anomalies from late spring to summer promote continuous sensible heating, which favors the maintenance of circulation anomalies. Consequently, a possible pathway via which spring snowmelt impacts the atmosphere has been basically established, but the more detailed pathway may need further discussion.

To elucidate the atmospheric circulation associated with EEWS spring snowmelt, the wind and geopotential height anomalies in the middle and low troposphere regressed onto DSWEI are presented in Fig. 7. In MJ, the EEWS snowmelt process tends to end, negative geopotential height anomalies appear over EEWS with increased snowmelt, and an evident quasi-barotropic structure is shown between the mid- and lower-level circulations. There also exists a baroclinic component, and the anomaly center tilts slightly to the west with altitude (Figs. 7a,c). Apparently, significant negative anomalies occupy EEWS at $1000 \mathrm{hPa}$, implying the anomalous cooling effect of the land on the atmosphere. In the middle troposphere, the extent of negative anomalies shrinks westward, with the center located west of that in the lower level. This structure reflects the contribution of surface thermal forcing, which facilitates the conversion from available potential energy to kinetic energy and thus promotes the development of quasi-stationary waves. It was also found that there are northerly wind anomalies from the Arctic region in the west of EEWS at lower troposphere, with the advection of cool air and moisture to EEWS, which can promote the maintenance of surface cold conditions. This temperature advection is somewhat similar to that associated with Arctic Oscillation (AO) or North Atlantic Oscillation (NAO), which can play an important role in surface air temperature anomalies and forcing the stationary wave pattern (Xie et al. 1999; Thompson and Wallace 2000). Therefore, these northerly advection anomalies may also be related to AO or NAO, and further affect the cooling in the lower troposphere over EEWS. Besides, accompanied by anomalous low pressure, strong southerly wind anomalies exist in east EEWS, favoring the subsequent snowmelt process in high latitudes. Meanwhile, the NEA region is largely controlled by positive geopotential height anomalies, with more significant anomalies occurring at $500 \mathrm{hPa}$ than at $1000 \mathrm{hPa}$.

In JJA, the spatial distribution of circulation resembles that in $\mathrm{MJ}$, but exhibits a seasonal evolution with the center shifting eastward, which is also revealed by previous studies (Wu et al. 2009; Mu and Zhou 2012). Yasunari et al. (1991) mentioned that the snow-related circulation shift may result from the lagged snow-hydrological effect after snowmelt. As illustrated by Fig. 7c, significant negative height anomalies are mainly located around EEWS in late spring. In summer, negative anomalies in EEWS weaken and move eastward to higher latitudes in western and central Siberia (Fig. 7d). Interestingly, this eastward shift accords closely with the Eurasian snowmelt process. As described above, more EEWS spring snowmelt is 

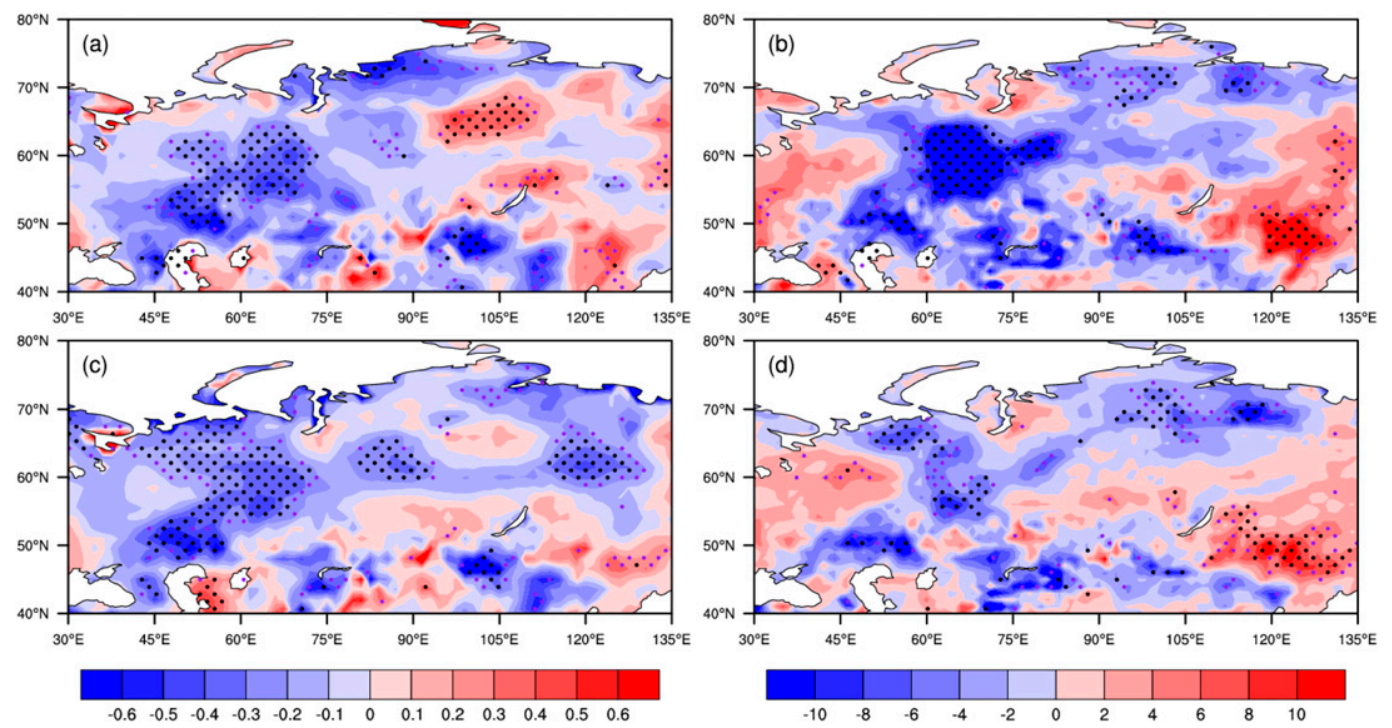

FIG. 6. Composite difference of (a),(c) land-atmosphere temperature difference (K) and (b),(d) surface upward sensible heat flux $\left(10^{6} \mathrm{~J} \mathrm{~m}^{-2}\right)$ between high and low DSWEI years in (a),(b) MJ and (c),(d) JJA. The black (purple) dotted areas exceed the $95 \%$ (90\%) confidence level based on the Student's $t$ test.

usually accompanied by less spring snowmelt in central Siberia according to EOF2 of the Eurasian spring snowmelt (Fig. 3b), which causes more residual snow in central Siberia and thereby leads to more snowmelt in the later period. Anomalous snowmelt change can affect soil moisture, and induce anomalous atmospheric response by modifying the land surface thermal condition. Previous analysis suggests that strong negative anomalies of surface upward sensible heat flux occupy EEWS in MJ, while those negative signals in central Siberia are relatively weak. The intensity of negative sensible heat anomalies in EEWS is weakened in summer compared with that in MJ, but it is sustained in central Siberia, generating continuous cooling to the atmosphere above. The variation characteristics of sensible heat flux anomalies are consistent
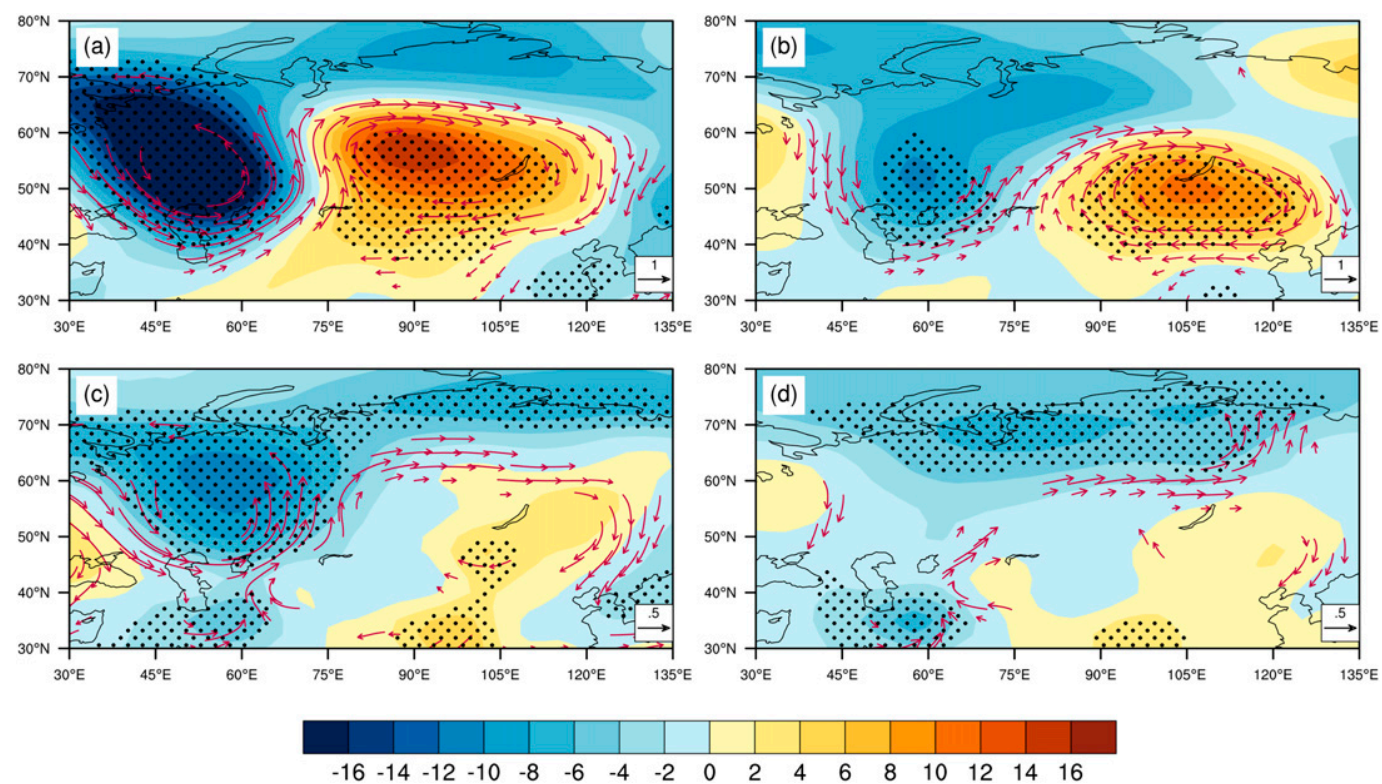

FIG. 7. Anomalies of (a),(b) 500-hPa geopotential height (shading; gpm) and wind (vectors; $\mathrm{m} \mathrm{s}^{-1}$ ), and (c),(d) 1000-hPa geopotential height (shading) and 850-hPa wind (vectors) in (a),(c) MJ and (b),(d) JJA regressed onto DSWEI. The dotted areas exceed the $95 \%$ confidence level based on the Student's $t$ test, and only wind vectors that are significant at the $90 \%$ confidence level are shown. 

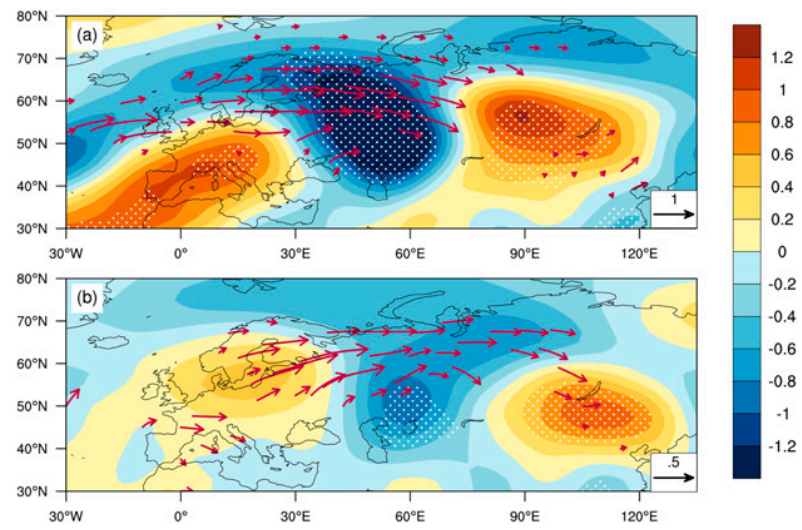

FIG. 8. Anomalies of (a) MJ and (b) JJA streamfunction (shading; $\mathrm{m}^{2} \mathrm{~s}^{-2}$ ) and wave activity flux (vectors; $10^{6} \mathrm{~m}^{2} \mathrm{~s}^{-1}$ ) at $500 \mathrm{hPa}$ regressed onto DSWEI. The dotted areas exceed the $95 \%$ confidence level based on the Student's $t$ test.

with the circulation changes in lower-level circulation, and also correspond to the temporal evolution of Eurasian snowmelt from west to east, and from the midhigh to high latitudes. This indicates that the temporal and spatial variations of snowmelt and the related surface variables may affect the atmospheric responses to the land surface, and then cause the eastward shift of circulations. With the increase of spring snowmelt over EEWS, there are also positive soil moisture anomalies and negative sensible heat flux anomalies over central Siberia, which may play an important role in the eastward shift of the negative geopotential height anomalies. As the upstream circulation system moves, the downstream circulation is adjusted accordingly. Significant positive height anomalies control NEA in summer with the center located in the south of Lake Baikal, which is to the southeast of that in MJ (Fig. 7b). A favorable circulation background is thus provided. Moreover, corresponding to the anomalous positive geopotential height in NEA, an anticyclonic circulation exists over Lake Baikal, with southerly wind anomalies prevailing on the west side to transport warm advection, which benefits NEA summer land surface warming.
Figure 8 depicts the 500-hPa streamfunction and WAF regressed onto DSWEI. The relatively weak Rossby wave train spreads eastward from the North Atlantic in MJ, grows over EEWS, and propagates downstream to eastern Eurasia (Fig. 8a). This pathway partly indicates the role of North Atlantic SST in influencing NEA climate as revealed by some previous studies (Dong et al. 2016; Hong et al. 2017; Sun et al. 2019b). Also, the growth of wave train over EEWS may be due to the westward tilting of the geopotential height (Ambrizzi and Hoskins 1997; Takaya and Nakamura 2001), which is associated with increased EEWS spring snowmelt. In summer, WAFs over the North Atlantic are weakened, and the wave train originated from western Europe propagates eastward to NEA through EEWS. Notably, western Europe and NEA are the regions of Eurasian surface warming, which are also two centers along the Rossby wave (Hong et al. 2017; Sun et al. 2019a). There is a wave source over Europe, with the divergence of WAFs there. Meantime, WAFs converge and diverge in the west and east of EEWS respectively, forming an anomalous wave source in EEWS, implying a reinforcement of the wave train there, and promoting the further convergence of the wave train into NEA. We noted that strengthened wave train in MJ is mainly located in west EEWS, while the WAF in JJA is amplified in the east of EEWS. Similar to the evolution of geopotential height anomalies in the low troposphere, the location where the wave train is intensified also shifts eastward as time progresses. Figure 9 further shows the zonal vertical section of streamfunction and WAF averaged along $55^{\circ}-70^{\circ} \mathrm{N}$. With increased EEWS spring snowmelt, the negative anomalies of streamfunction tilt westward greatly in the lower troposphere over EEWS, accompanied by vigorous vertical WAFs propagating upward from the lower to the middle troposphere, and then turning to the east (Fig. 9a). In JJA, the negative anomalies shift slightly eastward, and the west-tilting structure of streamfunction still exists with the upward WAFs, but the intensity is weaker than that in MJ. This westward tilt and upward fluxes can favor the development of the wave train (Iwao and Takahashi 2008), and thus the lower forcing and the middle-level circulation anomalies are linked. In addition, the

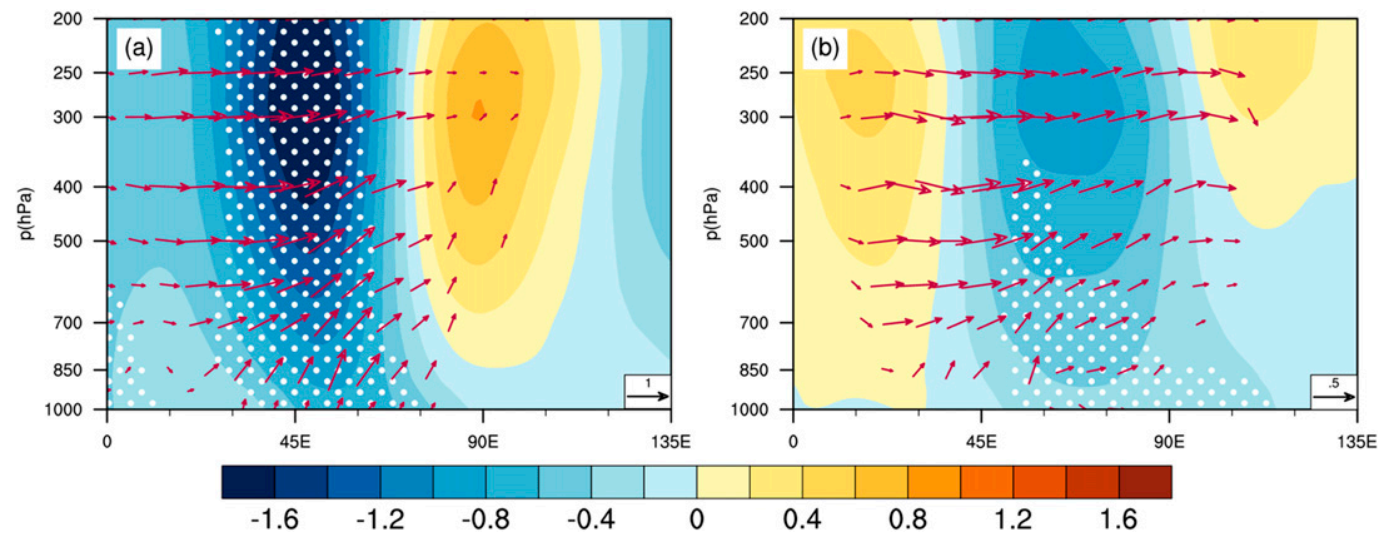

FIG. 9. Anomalies of longitude-pressure cross sections of (a) MJ and (b) JJA streamfunction (shading; $\mathrm{m}^{2} \mathrm{~s}^{-2}$ ) and wave activity flux (vectors; $10^{6} \mathrm{~m}^{2} \mathrm{~s}^{-1}$ ) averaged for $55^{\circ}-70^{\circ} \mathrm{N}$ latitude regressed onto DSWEI. The dotted areas exceed the $90 \%$ confidence level based on the Student's $t$ test. 
eastward propagation of wave trains in the middle troposphere further promotes the transmission of energy to downstream areas, thereby leading to the strengthening of the anticyclonic circulation anomalies around Lake Baikal. Therefore, the link between circulation anomalies in EEWS and NEA is established.

Some previous studies (Matsumura and Yamazaki 2012; Halder and Dirmeyer 2017) indicated that spring snowmelt modulates the large-scale circulation by affecting the surface heating to the atmosphere, which then influences the climate outside the snowmelt area. Hence, with the aforementioned analysis of circulation characteristics, a possible way for EEWS spring snowmelt to impact the downstream circulation in NEA is given as follows: The lower atmosphere responds directly to the anomalies of local intense snowmelt and relevant surface thermal variables. This anomalous response further spreads upward to the upper atmosphere through the upward WAFs in the lower-middle troposphere, intensifying the eastward wave train, amplifying the forcing signal in the middle troposphere. In addition, with growing EEWS snowmelt, the snowmelt in central Siberia in the later period also increases, which may anomalously reduce surface sensible heat flux and generate anomalous cooling to the atmosphere above as well as negative geopotential height anomalies there. Consequently, atmospheric anomalies occur in NEA through adjustment of circulation. The negative geopotential height anomalies over EEWS are accompanied by anomalous southerly wind in the east, which favors the development of anticyclonic circulation and anomalous positive geopotential height over NEA. Besides, the anomalous circulation extends from the lower to the middle troposphere, with westward tilting structure and vigorous upward WAFs, reinforcing the eastward wave train in EEWS, leading to anticyclonic circulation anomalies in the downstream around Lake Baikal, which facilitate the NEA land surface warming.

In summer, corresponding to the anomalous circulation in NEA, an abnormal vertical motion ensues. As shown in Fig. 10a, significant positive anomalies associated with increased DSWE control the troposphere over NEA, with the center located at $200-300 \mathrm{hPa}$. Accordingly, obvious descending motions appear below the anomalous high pressure center, which leads to adiabatic heating and is conducive to temperature rise there. Figure 10c shows that the temperature in the whole troposphere is anomalously high in the latitudinal range of NEA $\left(35^{\circ}-60^{\circ} \mathrm{N}\right)$, and the warm center appears in the lower troposphere where the downdraft is enhanced. Previous studies have indicated that abnormal descending motion of largescale background circulation can cause the anomalous adiabatic warming (Chen et al. 2020; Yao et al. 2020), and the anomalous vertical motion in this study could be a reason for surface warming over NEA. Figure $10 \mathrm{~b}$ depicts the $500-\mathrm{hPa}$ vertical velocity anomaly field. Corresponding to one warming center in Fig. 1a, significant anomalies are mainly in the southeast of Lake Baikal. As mentioned before, with increased EEWS snowmelt, an anticyclonic circulation occurs in summer over NEA, while a northerly airflow prevails on its east side, which hampers the land surface warming there. Therefore, the temperature rise in this region depends more on dynamic effect. The strong descending motions there generate adiabatic heating, thereby promoting LST increase in the southeast of Lake Baikal. For another warming center in the southwest of Lake Baikal, the vertical motions are relatively weak. But in the rear of anomalously high pressure, the southerly wind can bring warm air to this region, and the maximum of warm advection transportation coincides with the surface warming center (Fig. 10e), which indicates the advection effect is more crucial to land surface warming there.

Previous studies have emphasized the impact of cloud cover on LST (Dai et al. 1999; Betts et al. 2014; Ye et al. 2015). Decrease in cloud cover can induce an increase of shortwave radiation received by the surface, which then causes land surface warming. Figures $10 \mathrm{~d}$ and $10 \mathrm{f}$ display the distributions of total cloud cover and incident solar radiation regressed onto DSWEI. Apparently, significant negative cloud-cover anomalies and positive shortwave radiation anomalies emerge in the southeast of Lake Baikal, suggesting that with the anomalously high EEWS spring snowmelt, the NEA cloud cover is abnormally low in summer, and the incident shortwave radiation increases. Additionally, the cloud-cover anomalies also correspond to the $500-\mathrm{hPa}$ vertical velocity anomalies. The abnormal sinking inhibits cloud-cover formation, promoting shortwave radiation absorption at the surface, and favoring land surface warming, which provides further explanation for the influence of spring snowmelt on summer LST.

Besides the remote forcing of spring snowmelt over EEWS, some local land surface factors that may potentially affect the NEA LST also deserve attention. With increased EEWS spring snowmelt, the surface variables over NEA change correspondingly. It is noted that there are significant negative anomalies in soil moisture (Fig. 5), some positive anomalies in land-atmosphere temperature difference, and upward sensible heat flux (Fig. 6) around Lake Baikal in MJ and JJA. We also investigated the connection between some surface variables and LST, and found a close relationship. The anomalously dry soil is accompanied by reduced latent heat flux and increased sensible heat flux, and further favors surface warming over NEA. The detailed physical mechanism of the NEA land surface warming affected by local processes has been proven in our previous work (Chen et al. 2020). In addition, there are interactions between the land and the atmosphere (Seneviratne et al. 2010; Koster et al. 2016; Sato and Nakamura 2019). We mainly explored the role of the anomalous circulation in the surface warming in this section, but the feedback of the land surface on the atmosphere also cannot be denied. As shown in Figs. $6 \mathrm{~b}$ and $6 \mathrm{~d}$, there are positive anomalies of surface upward sensible heat flux on the east side of Lake Baikal, implying the increased heating to the atmosphere above. We also examined the relationship between NEA LST and sensible heat flux and found that surface warming is closely related upward sensible heat. This increased upward heating associated with surface warming promotes the maintenance of anomalous anticyclonic circulation over NEA, which in turn facilitates land surface warming.

\section{Model simulations}

In the previous section, the possible pathway for the impact of EEWS spring snowmelt on NEA summer climate is 

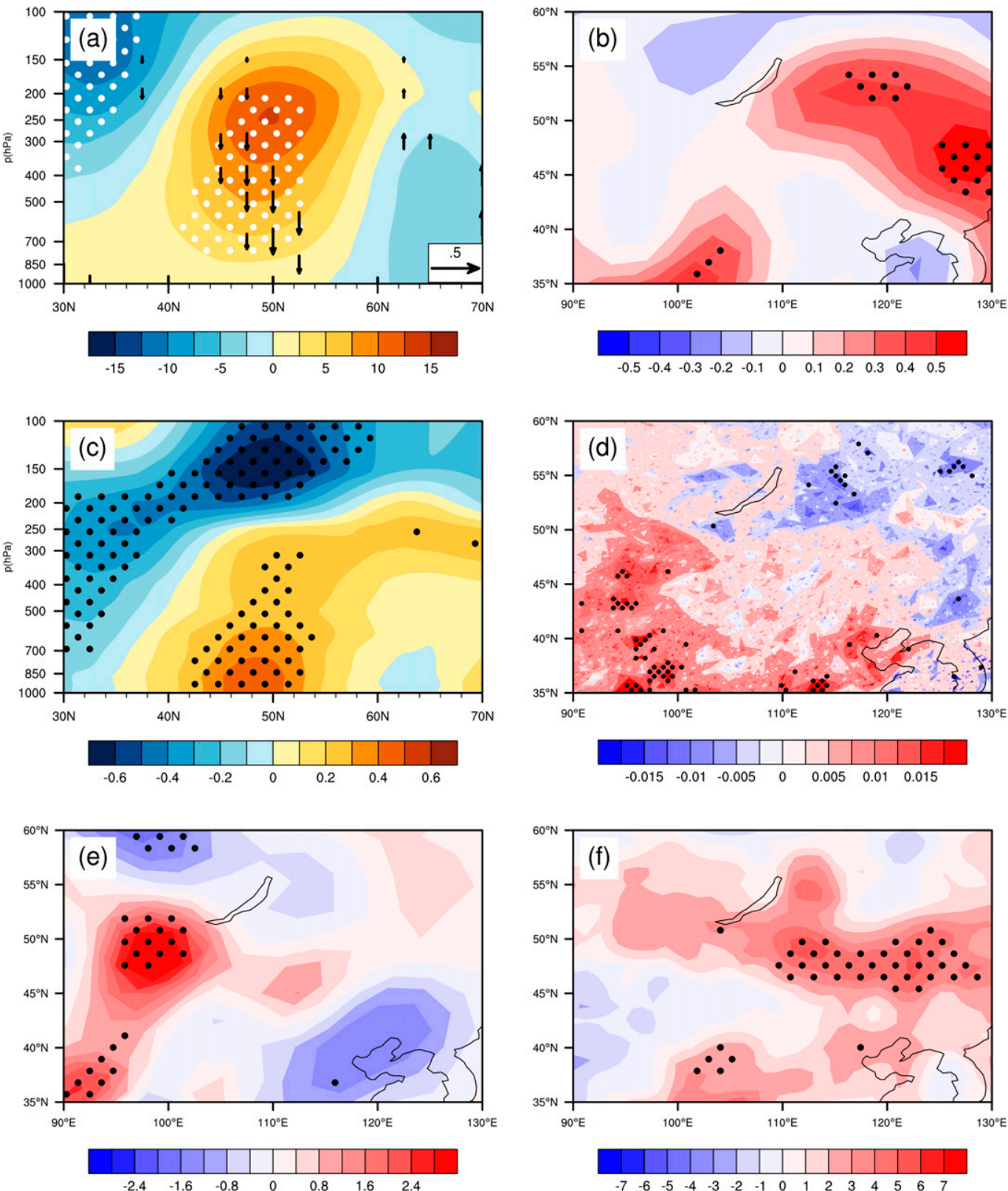

FIG. 10. Anomalies of (a) geopotential height (shading; gpm) and vertical velocity (vectors; $\mathrm{Pa} \mathrm{s}^{-1}$ ) and (c) air temperature $(\mathrm{K})$ in the vertical-horizontal cross section averaged along $90^{\circ}-130^{\circ} \mathrm{E}$, (b) 500 -hPa vertical velocity $\left(\mathrm{Pa} \mathrm{s}^{-1}\right)$, (d) cloud fraction (\%), (e) 850-hPa temperature advection $\left(10^{-6} \mathrm{~K} \mathrm{~s}^{-1}\right)$, and (f) downward shortwave radiation in JJA. The dotted areas exceed the 95\% confidence level based on the Student's $t$ test.

presented based on statistical methods. It is difficult to isolate the role of snowmelt and soil moisture changes in the observational analysis. To verify this possible way, we utilized CESM1.2.2 to conduct numerical experiments. A set of sensitivity experiments was designed to characterize EEWS snowmelt anomalies, and the difference between the CTL and SNO experiments was further analyzed.

To prove the feasibility of the experimental design, we evaluated the difference in SWE and DSWE (SNO run minus
CTL run) in spring (Fig. 11). The DSWE anomalies in the reanalysis and model results are basically consistent, with largescale significant signals found over EEWS, and their spatial ranges and magnitudes also match (Figs. 11a,b). In addition, since the defined spring snowmelt is related to the SWE in March and May, the SWE anomalies in these two months were also shown, in order to simulate the spring snowmelt process better. Observations suggest that more spring snowmelt corresponds to more SWE in the entire EEWS in March and less 

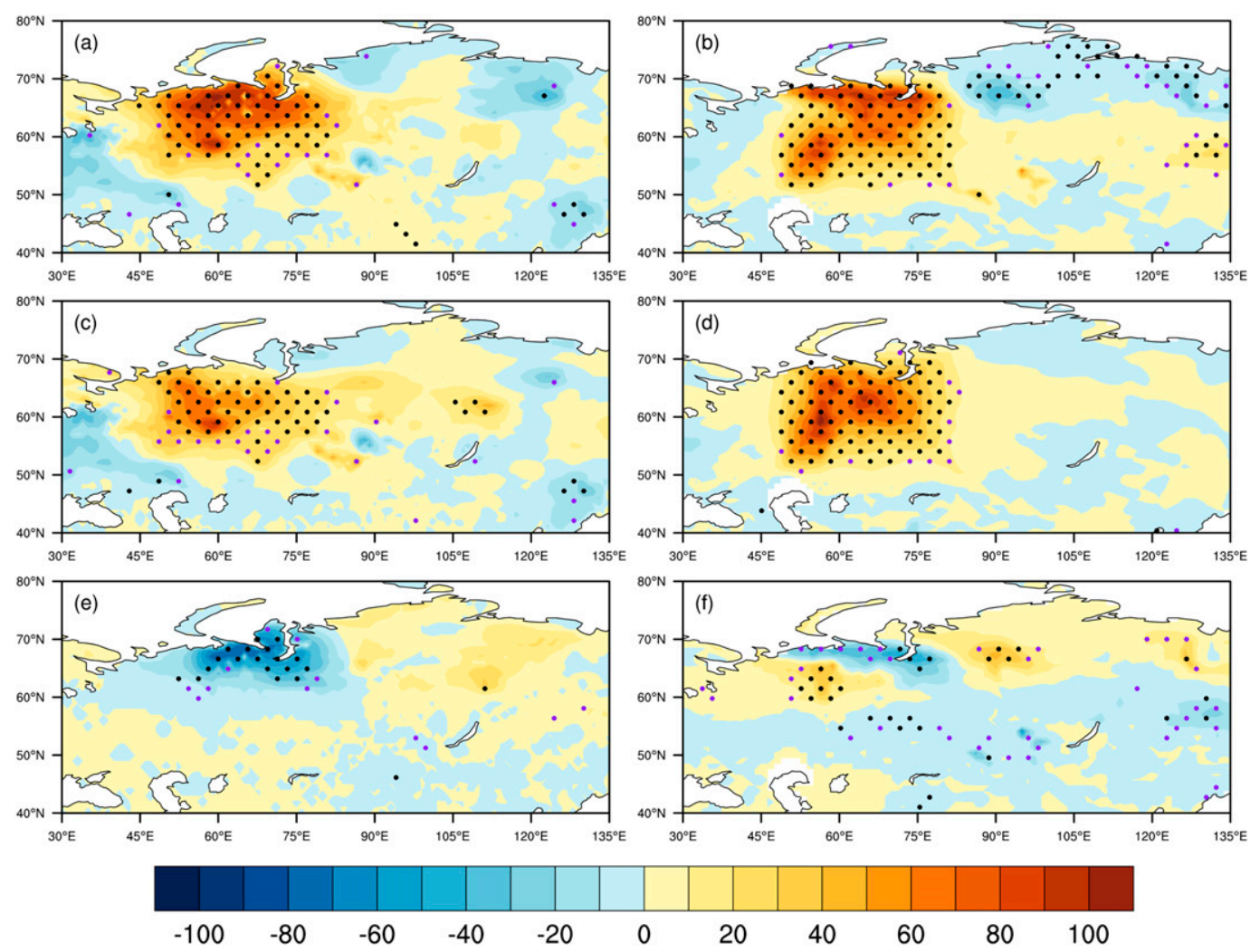

FIG. 11. Differences of (a),(b) spring DSWE, (c),(d) March SWE, and (e),(f) May SWE (mm) in (left) observations (high and low DSWEI years) and (right) simulations (SNO runs minus CTL runs). The black (purple) dotted areas exceed the $95 \%(90 \%)$ confidence level based on the Student's $t$ test.

SWE in northern EEWS in May. In the simulations, positive SWE anomalies exist during March in EEWS, whose distribution is same to the observation results, except a slightly higher central intensity (Figs. 11c,d). For SWE in May, the model can simulate the reduction in north EEWS, but there are some differences compared with the characteristics shown in observations: The simulated negative anomalies in May are smaller than observations, while some positive signals still exist on the west side of EEWS in the model results (Figs. 11e,f). In general, although the model simulations cannot completely agree with the observations, they basically reproduce the characteristics of the relationship between EEWS snowmelt and NEA summer LST, indicating that modifying snowfall and snow albedo to characterize spring snowmelt is feasible.

To confirm whether snowmelt can affect the atmosphere through influencing the land surface thermal conditions, we first discussed the related surface variable anomalies in the model results. Figure 12 shows the fields of simulated soil moisture and surface sensible heat. It replicates variations of land surface variables corresponding to the spring snowmelt changes. As illustrated by Figs. $12 \mathrm{a}$ and $12 \mathrm{c}$, positive signals of soil moisture occur in EEWS. We also calculated the persistence time scale of simulated soil moisture and found it can persist from late spring to summer (figure not shown). In addition to EEWS, it was also found that there is a good persistence of simulated soil moisture over northeastern Russia, which may be relevant to the permafrost but not the soil moisture itself over this region (Biskaborn et al. 2019). The range of positive values expands in summer, and extends to central Siberia. Some negative signals appear near the Ob Bay in summer, which may be due to lower snowmelt at high latitudes in May. In addition, there are persistent negative soil moisture values around Lake Baikal and the western part of eastern Europe. Correspondingly, the EEWS surface sensible heat flux also shows negative anomalies. In MJ, significant negative signals emerge in the south part of EEWS and western central Siberia (Fig. 12b), which cools the upper atmosphere. A small range of positive anomalies appear in the northern part of EEWS, perhaps due to the reason that the snow has not completely melted at this time with an ongoing melting process. Associated with the negative soil moisture anomalies, some positive sensible heat flux values also exist in over the East European Plain and Lake Baikal. In JJA (Fig. 12d), the entire EEWS is almost occupied by negative signals of sensible heat flux, which continue to cool the atmosphere. Comparison between the simulation and reanalysis results shows some differences in intensity and scope. In the simulation results, the range and significance of positive soil moisture anomalies are relatively small, and the positive anomalies in the south of EEWS and central Siberia are not obvious. As for surface sensible heat, the simulated negative center is slightly eastward compared with that of the reanalysis results, and the negative 

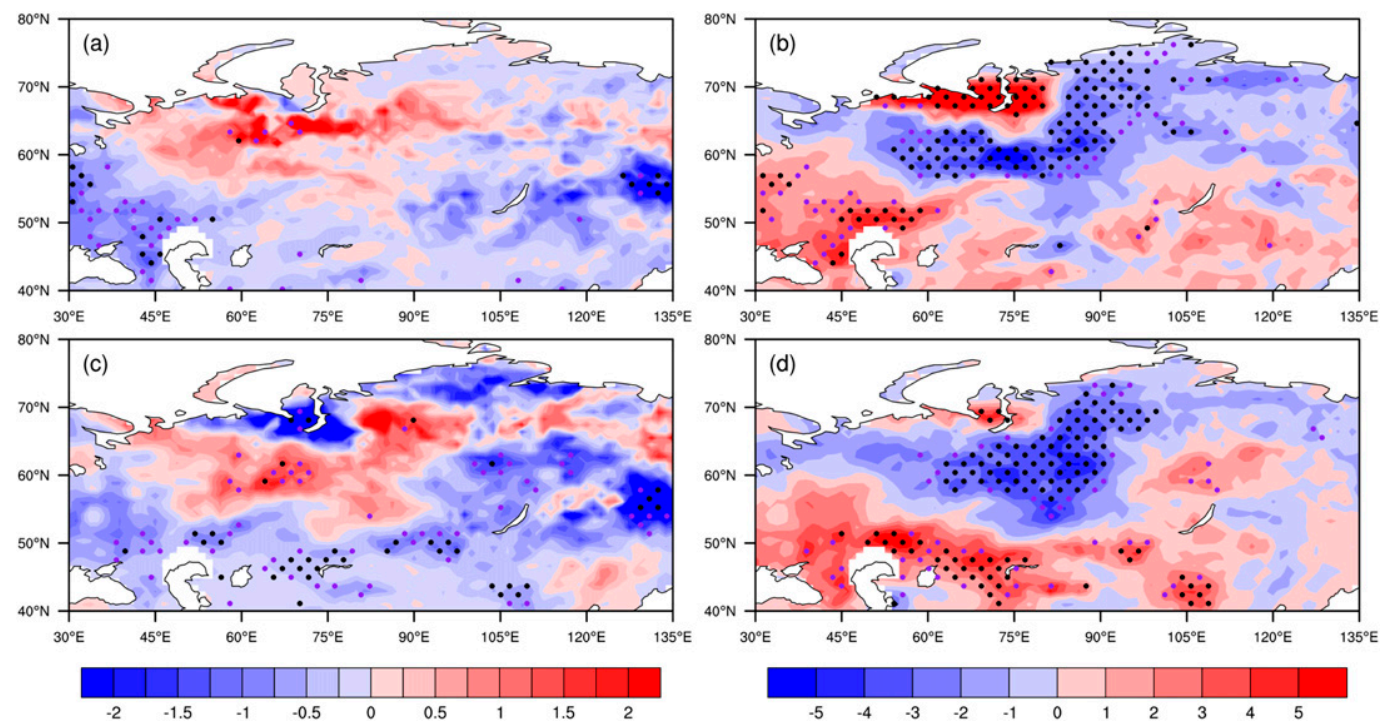

FIG. 12. Simulated differences (SNO runs minus CTL runs) of (a),(c) soil moisture $\left(\mathrm{kg} \mathrm{m}^{-2}\right.$ ) and (b),(d) surface upward sensible heat flux $\left(\mathrm{W} \mathrm{m}^{-2}\right)$ in (a),(b) MJ and (c),(d) JJA. The black (purple) dotted areas exceed the $95 \%$ $(90 \%)$ confidence level based on the Student's $t$ test.

signals in central Siberia are also weaker. But generally speaking, the simulation results can reflect the main characteristics of relevant surface variables in reanalysis results. The sensible heat flux signals basically correspond to those of soil moisture. The increase of soil moisture associated with increased DSWE tends to induce an anomalous negative sensible heat flux, which denotes the reduction in sensible heat transported from the land surface to the atmosphere. And the persistent soil moisture anomalies from late spring to summer lead to continuous cooling to the atmosphere, which is consistent with previous observations.

To explore the possible response of the atmosphere to changes in simulated land surface variables, the simulated distributions of $500-\mathrm{hPa}$ geopotential height are shown in Fig. 13. Corresponding to anomalous cooling from the surface, negative anomalies exist in EEWS, while significant positive anomalies occur downstream around Lake Baikal (Fig. 13a). In JJA (Fig. 13b), anticyclonic circulation anomalies are still maintained over EEWS, with the same intensity and location as these in $\mathrm{MJ}$, indicating that the upper atmosphere over EEWS generates a stable response to the surface thermal anomalies. In the downstream of EEWS, the areas of positive geopotential height anomalies expand northward. There are two centers in the north of Lake Baikal and eastern central Siberia respectively, making the whole area of central and eastern Eurasia controlled by anticyclonic circulation anomalies. We found that the simulated circulation patterns are basically consistent in MJ and JJA, but a certain eastward shift exists in the reanalysis results, indicating that the simulated NEA summer circulation is westward of that in the reanalysis; its positive anomaly areas, which have large meridional spans, are more like the combination of the two positive anomaly areas over Lake Baikal and northeastern Eurasia in the reanalysis results. But undeniably, the model can still simulate the zonal dipole pattern of circulation, with anomalous low pressure located in EEWS and anomalous high pressure over the downstream Baikal region. The simulated summer WAF fields also show an eastward propagation (Fig. 14). Corresponding to the negative anomalies of surface sensible heat, the WAF is strengthened in EEWS, resulting in the formation of an anomalous wave source, which splits into two branches to spread downstream. One extends northeast, and the other spreads southeast to the Baikal region and converges there. These further reflect the impact of spring snowmelt on the reinforcement of EEWS wave train and the downstream circulation changes.

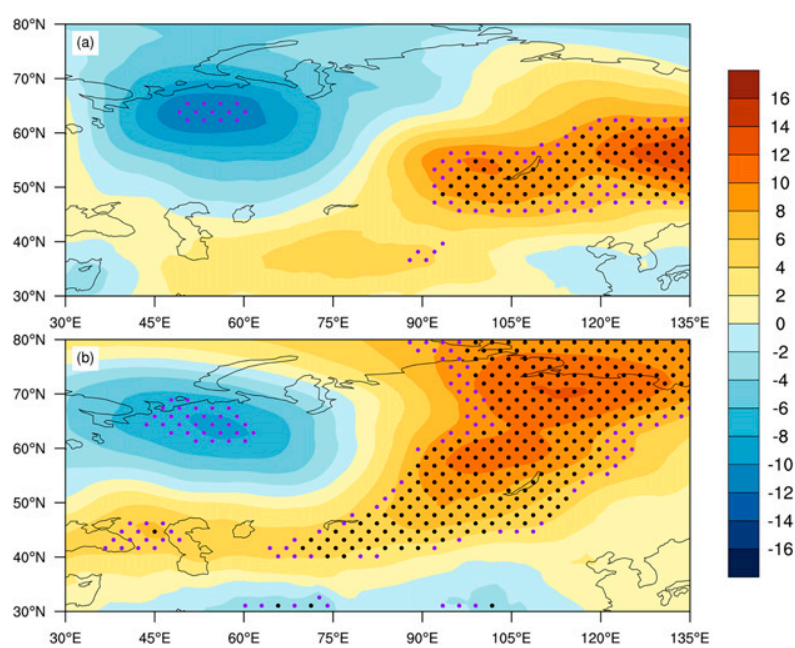

FIG. 13. Simulated differences (SNO runs minus CTL runs) of geopotential height (gpm) at $500 \mathrm{hPa}$ in (a) MJ and (b) JJA. The black (purple) dotted areas exceed the $95 \%$ (90\%) confidence level based on the Student's $t$ test. 


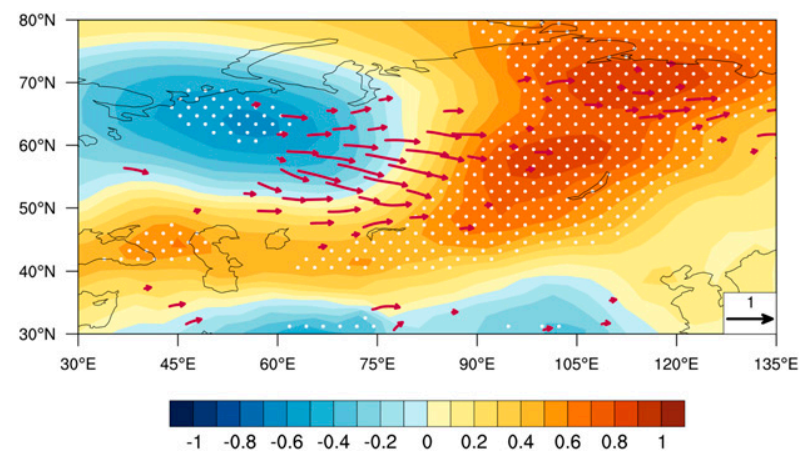

FIG. 14. Simulated differences (SNO runs minus CTL runs) of 500-hPa streamfunction (shading; $\mathrm{m}^{2} \mathrm{~s}^{-2}$ ) wave activity flux (vectors; $10^{6} \mathrm{~m}^{2} \mathrm{~s}^{-1}$ ) in JJA. The dotted areas exceed the $90 \%$ confidence level based on the Student's $t$ test.

The summer LST associated with anomalous EEWS spring snowmelt in simulation is shown by Fig. 15. Significant positive anomalies appear around Lake Baikal with two large value centers in the south and southwest of Lake Baikal, while negative anomalies occur in EEWS. The distribution accords with the simulation of circulation anomalies. Compared with reanalysis results (Figs. 1a and 4a,b), the location of positive anomalies in NEA simulated is slightly westward, which may be caused by the difference in circulation over there. Although there is a certain shift in location, the response of summer LST in NEA to spring snowmelt in EEWS is roughly in accord with the reanalysis results, and the basic feature of anomalous high surface temperature around Lake Baikal still exists.

In general, model simulations can reproduce the reanalysis results and corroborate the possible influence pathway and related physical mechanisms derived from previous statistical analysis. EEWS spring snowmelt has been confirmed to play an important role in NEA summer land surface warming.

\section{Discussion}

In the previous sections, we found a close relationship between EEWS spring snowmelt and NEA summer LST based on observational analysis, and utilized CESM1.2.2 to verify the statistical results. The simulations show that increased EEWS snowmelt results in elevated NEA temperature, and the possible influence pathway has been basically confirmed. However, undeniable differences exist between results of simulations and reanalysis, making the position of simulated surface temperature anomalies shift. The possible causes of these differences are worth further exploration, which can facilitate the understanding of snowmelt-related processes.

We noted that there are some differences between the simulated SWE and observations in May. Although most of the snow has melted in May and the simulated DSWE is also close to the observations, these differences may still affect the subsequent anomalies of land surface variables. Simulation of SWE in May shows weak negative signals, and some positive signals even appear in west EEWS (Fig. 11f), which may be caused by the anomalous early snowfall increase. Despite the snowmelt process there, the positive signals can hardly be

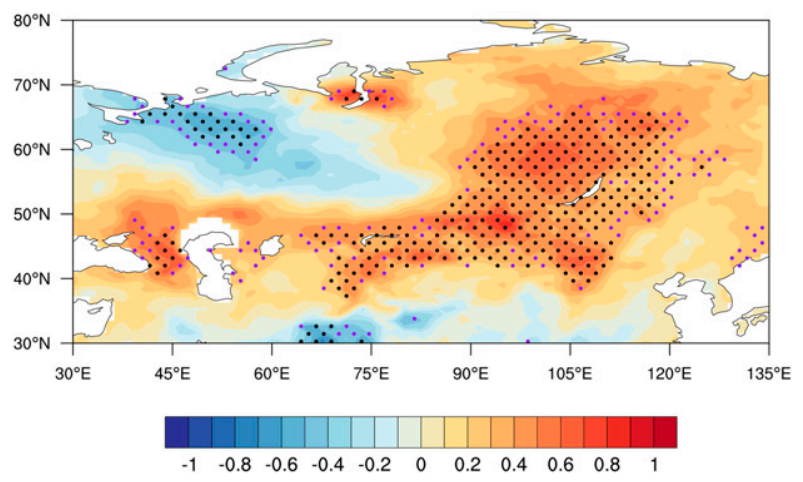

FIG. 15. Simulated differences (SNO runs minus CTL runs) of LST (K) in JJA. The black (purple) dotted areas exceed the $95 \%$ $(90 \%)$ confidence level based on the Student's $t$ test.

reduced remarkably in the later period (Flanner and Zender 2005). The positive SWE anomalies in May were found to relate to the high SWE values in March, which supports the above view. Besides, as mentioned before, we reduced SWE by changing the EEWS snow albedo, and the results show that significant snow albedo anomalies are mainly in northeast EEWS (figure not shown), while in the rest of the EEWS region those anomalies are weak, which may be another reason for the positive SWE signals in May.

About the simulated soil moisture, its intensity is relatively weak, which may be related to the simulated weak negative signals of SWE in May. It was also noticed that the range of positive soil moisture anomalies in simulations is relatively small. In the reanalysis results, some significant positive anomalies exist in south EEWS around $50^{\circ} \mathrm{N}$, which are not well presented in the simulations. A reason may be that we only focused on the abnormal signals in the key snowmelt region in the SNO experiments, and ignored the SWE changes in other Eurasian regions. Despite the insignificant effect of snowmelt in other regions on NEA summer LST, there may still be some connections in the SWE changes of various Eurasian regions (Yim et al. 2010; Wu et al. 2014a), which cannot be fully reflected in the simulation. Additionally, Eurasian snow usually melts in spring, so this study paid more attention to spring snowmelt. However, the melting period differs in different areas. In particular, snowmelt occurs earlier in relatively low latitudes (e.g., north of the Caspian Sea around $50^{\circ} \mathrm{N}, \mathrm{NEA}$ ); in some higher-latitude regions, the snowmelt process can persist into summer (Matsumura and Yamazaki 2012; Wu and Chen 2016). When conducting the sensitivity experiments, we mainly considered the most typical characteristics of SWE changes. It is difficult to replicate the complex Eurasian snowmelt processes in detail, which may cause deviations in some snow-related variables.

By comparison, it was found that the main difference in the circulation between the simulations and observations is whether an eastward shift occurs with the seasonal transition, which may be connected with the differences in surface sensible heat anomalies. The simulated negative sensible heat anomalies have good persistence in EEWS, but the anomalies in central Siberia are not significant. This may result in an anomalous low pressure maintained stably over EEWS and 

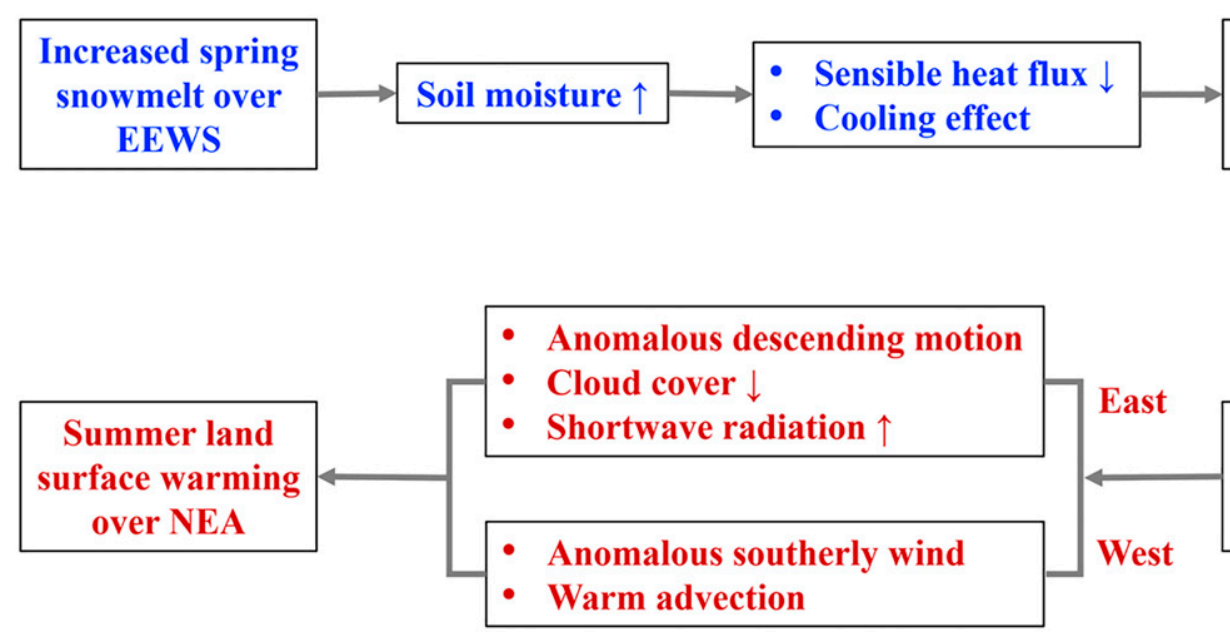

Negative geopotential
height anomalies over
EEWS

Eastward-propagating wave train

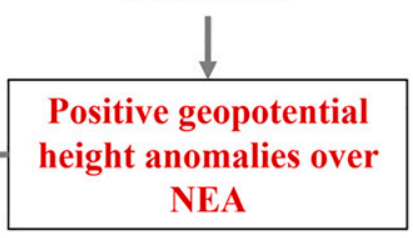

FIG. 16. Schematic of the process in which EEWS spring snowmelt affects NEA summer land surface warming.

hinder the eastward propagation of circulation. The simulated positive sensible heat flux anomalies from the Caspian Sea to Lake Balkhash promote the formation of positive geopotential height there, which is south of the positive circulation anomaly in the East European Plain in reanalysis results, and lead to a combination of positive geopotential heights at low latitudes. Meanwhile, we noted that the simulated geopotential height anomalies shift northward compared with the observations, which may be due to the differences in the extent of soil moisture anomalies. The anomalous positive soil moisture signals in simulations only appear in EEWS, while there are also some positive anomalies in central Siberia and south of EEWS in observations. These differences can cause different surface thermal conditions and the heating to the atmosphere, and then lead to a northward shift of simulated circulations. Besides, some studies found that snow cover on the Tibetan Plateau significantly influences the NEA summer climate (Zhao et al. 2007; Wu et al. 2016). This article mainly focuses on Eurasian snow, and whether the snow-cover changes on the Tibetan Plateau play an important role in causing these circulation differences is also worth further exploration. We checked the relationship between EEWS spring snowmelt and the snow cover on the Tibetan Plateau and found a significant positive correlation in March, which is a possible cause for the circulation difference. The NEA summer LST anomaly corresponds to the anomalous circulation change over there, and thus the simulated center of land surface warming shifts westward due to the relevant circulation differences. In general, it is inevitable that there are certain differences between the simulation and the observation, and we have discussed the possible causes of these difference, but it is difficult to solve the problem in the current situation. Nevertheless, the simulation can basically reproduce the main features of the observation, which indicates that the physical process proposed in the observation is reasonable.

\section{Conclusions}

Based on the FMI SWE data, ERA-Interim data, and CESM1.2.2 model, we explored the relationship between EEWS spring snowmelt and NEA summer LST and its associated physical processes. The results show a significant positive correlation between the first mode of NEA summer LST and the second mode of Eurasian spring snowmelt. The correlation coefficient between DSWEI and LSTI is 0.54, passing the significance test at the $95 \%$ confidence level. Spring snowmelt can amplify the wave train above it through changing the surface thermal conditions, and thus affects the NEA summer climate.

The processes of EEWS spring snowmelt affecting summer LST over NEA are shown in Fig. 16. The increased DSWE in EEWS tends to induce the anomalous increase of soil moisture, changing the local surface thermal conditions and resulting in a lower surface temperature compared to the upper atmosphere and decrease of the land-atmosphere temperature difference. Consequently, there exists a reduced upward sensible heat flux, indicating an anomalous cooling of the lower troposphere by the land surface, which causes the changes in atmospheric thickness between the lower and middle troposphere, and thereby leads to negative geopotential height anomalies in the middle troposphere. With the persistence of soil moisture from late spring to summer, the surface anomalously cools the above atmosphere continuously, causing an anomalous atmospheric response, and then making the geopotential height decrease extend to the upper troposphere. Meanwhile, with more EEWS spring snowmelt, obvious positive soil moisture anomalies and negative sensible heat anomalies also occur and persist over central Siberia, promoting cooling of the atmosphere and the geopotential height reduction therein, and inducing the eastward shift of circulation from spring to summer. Through investigation of wave propagation, we found that there is an anomalous wave source around EEWS, with a divergence of WAFs. Due to the cooling effect of snowmelt, the anomalous signals from the land surface gradually spread upward to the atmosphere over EEWS, accompanied by westward tilting of streamfunction and vertical WAFs propagating upward from the lower to the middle troposphere, and thus the wave train is strengthened there and continues to propagate eastward in the middle troposphere, promoting positive geopotential height anomalies in the downstream through the adjustment of circulation. This anomalous high pressure remains 
over NEA in summer, accompanied by an anomalous anticyclonic circulation. Subsequently, the causes of local surface warming in NEA were discussed. The southerly wind in the west of the anomalous anticyclonic circulation transfers warm air to NEA. On the other hand, the anomalous high pressure is accompanied by descending motion, which favors the anomalous temperature increase in the lower troposphere through adiabatic heating. Moreover, the descending motion can inhibit the cloud-cover generation, promoting the land surface absorption of shortwave radiation. All these provide favorable conditions for the NEA land surface warming, and LST increase is shown in the entire region around Lake Baikal. When the DSWE is anomalously low in spring, the opposite is true.

Numerical simulations also confirm the possible influence of spring snowmelt on summer surface warming. After considering the forcing of positive DSWE anomalies in EEWS, the land surface elements and atmospheric circulation change obviously. Specifically, soil moisture increases and the surface upward sensible heat flux decreases in EEWS. The simulated soil moisture anomalies can persist from late spring to summer, which promotes the persistence of anomalous sensible heat flux, and resulting in continuous cooling of the atmosphere from late spring to summer. CESM1.2.2 also simulates the response of the atmospheric circulation to the forcing of land surface thermal anomalies. The geopotential height decreases anomalously in EEWS and increases anomalously in NEA. The maintenance of this pattern promotes the formation of anomalous land surface warming in NEA. Thereby the anomalous increase of LST near Lake Baikal can be well simulated, but there is a certain deviation in the spatial position.

Our study investigated the causes of anomalous summer land surface warming in NEA from the perspective of spring snowmelt, and pointed out that Eurasian spring snowmelt can act as an important signal source for summer climate prediction, thus providing a new perspective on the NEA summer land surface warming. We used statistical methods to discover the relationship between EEWS spring snowmelt and summer LST around Lake Baikal, and explored the possible way in which EEWS spring snowmelt affects NEA summer climate through numerical simulation. However, there is a strong interaction between snow and atmosphere. $\mathrm{Xu}$ and Dirmeyer (2011, 2013) found that the snow-atmosphere coupling is strong during snowmelt and the later period. Therefore, the complex feedback process between snowmelt and the atmosphere is also worth of further study. In addition, we noticed that previous studies mainly emphasized the roles of SST and SIC forcings in land surface warming in NEA, while recent studies suggested that Eurasian snow is also related to changes of SST and SIC. For instance, Sun et al. (2019) pointed out that the North Atlantic SST anomaly has an important influence on the decadal variation of dominant modes of winter Eurasian SWE. Li et al. (2018) found a close relationship between Arctic sea ice in March and snow depth in April. Given that, what is the relationship between spring snowmelt and pre-snowmelt factors such as SST and SIC? What role does snowmelt play in the effects of SST and SIC on the land surface thermal conditions and summer climate in NEA? These all need further exploration.
Acknowledgments. This work was jointly supported by NSFC (42088101, 41625019, 42021004) and the NUIST-UoR International Research Institute Research Fund. (The FMI SWE data are available at http://www.globsnow.info/, the ERA-Interim dataset is from https://apps.ecmwf.int/datasets/, the NCEPNCAR reanalysis dataset is available at https:/psl.noaa.gov/data/ gridded/data.ncep.reanalysis.html, and the AVHRR PATMOS-x dataset is provided by NOAA at https://www.ncdc.noaa.gov/cdr/ atmospheric/avhrr-cloud-properties-patmos-x.)

\section{REFERENCES}

Ambrizzi, T., and B. J. Hoskins, 1997: Stationary Rossby-wave propagation in a baroclinic atmosphere. Quart. J. Roy. Meteor. Soc., 123, 919-928, https://doi.org/10.1002/qj.49712354007.

Andrews, T., J. M. Gregory, P. M. Forster, and M. J. Webb, 2012: Cloud adjustment and its role in $\mathrm{CO}_{2}$ radiative forcing and climate sensitivity: A review. Surv. Geophys., 33, 619-635, https://doi.org/10.1007/s10712-011-9152-0.

Barnett, T. P., L. Dümenil, U. Schlese, E. Roeckner, and M. Latif, 1989: The effect of Eurasian snow cover on regional and global climate variations. J. Atmos. Sci., 46, 661-686, https://doi.org/ 10.1175/1520-0469(1989)046<0661:TEOESC $>2.0$.CO;2.

Betts, A. K., R. Desjardins, D. Worth, and B. Beckage, 2014: Climate coupling between temperature, humidity, precipitation, and cloud cover over the Canadian Prairies. J. Geophys. Res. Atmos., 119, 13 305-13 326, https://doi.org/ 10.1002/2014JD022511.

Biskaborn, B. K., and Coauthors, 2019: Permafrost is warming at a global scale. Nat. Commun., 10, 264, https://doi.org/10.1038/ s41467-018-08240-4.

Blanford, H. F., 1884: On the connexion of the Himalaya snowfall with dry winds and seasons of drought in India. Proc. Roy. Soc. London, 37, 3-22, https://doi.org/10.1098/rspl.1884.0003.

Chen, H. S., D. Qi, and B. Xu, 2013: Influence of snow melt anomaly over the mid-high latitudes of the Eurasian continent on summer low temperatures in northeastern China (in Chinese). Chin. J. Atmos. Sci., 37, 1337-1347.

—, F. D. Teng, W. X. Zhang, and H. Liao, 2017: Impacts of anomalous midlatitude cyclone activity over East Asia during summer on the decadal mode of East Asian summer monsoon and its possible mechanism. J. Climate, 30, 739-753, https:// doi.org/10.1175/JCLI-D-16-0155.1.

—, W. X. Zhang, B. T. Zhou, F. D. Teng, J. Zhang, and Y. Zhou, 2019: Impact of nonuniform land surface warming on summer anomalous extratropical cyclone activity over East Asia. J. Geophys. Res. Atmos., 124, 10306-10320, https://doi.org/ 10.1029/2018JD030165.

- B. Yu, B. Zhou, W. Zhang, and J. Zhang, 2020: Role of local atmospheric forcing and land-atmosphere interaction in recent land surface warming in the midlatitudes over East Asia. J. Climate, 33, 2295-2309, https://doi.org/10.1175/JCLI-D-180856.1 .

Chen, W., and R. Y. Lu, 2014a: A decadal shift of summer surface air temperature over Northeast Asia around the mid-1990s. Adv. Atmos. Sci., 31, 735-742, https://doi.org/10.1007/s00376013-3154-4.

$\longrightarrow$, and $-2014 \mathrm{~b}$ : The interannual variation in monthly temperature over Northeast China during summer. Adv. Atmos. Sci., 31, 515-524, https://doi.org/10.1007/s00376-013-3102-3.

_ , and Coauthors, 2016: Variation in summer surface air temperature over Northeast Asia and its associated circulation 
anomalies. Adv. Atmos. Sci., 33 (1), 1-9, https://doi.org/ 10.1007/s00376-015-5056-0.

Chen, X. F., and W. L. Song, 2000: Circulation analysis of different influence of snow cover over the Tibetan Plateau and Eurasia in winter on summertime droughts and floods of China (in Chinese). Chin. J. Atmos. Sci., 24, 585-592.

Cohen, J., and D. Rind, 1991: The effect of snow cover on the climate. J. Climate, 4, 689-706, https://doi.org/10.1175/15200442(1991)004<0689:TEOSCO > 2.0.CO;2.

Dai, A., K. E. Trenberth, and T. R. Karl, 1999: Effects of clouds, soil moisture, precipitation, and water vapor on diurnal temperature range. J. Climate, 12, 2451-2473, https://doi.org/ 10.1175/1520-0442(1999)012<2451:EOCSMP > 2.0.CO;2.

Dee, D. P., and Coauthors, 2011: The ERA-Interim reanalysis: Configuration and performance of the data assimilation system. Quart. J. Roy. Meteor. Soc., 137, 553-597, https://doi.org/ 10.1002/qj.828.

Dey, B., and O. S. R. U. Bhanu Kumar, 1982: An apparent relationship between Eurasian spring snow cover and the advance period of the Indian summer monsoon. J. Appl. Meteor., 21, 1929-1932, https://doi.org/10.1175/1520-0450(1982)021<1929: AARBES $>2.0 . \mathrm{CO} ; 2$.

Dong, B. W., R. T. Sutton, W. Chen, X. D. Liu, R. Y. Lu, and Y. Sun, 2016: Abrupt summer warming and changes in temperature extremes over Northeast Asia since the mid-1990s: Drivers and physical processes. Adv. Atmos. Sci., 33, 10051023, https://doi.org/10.1007/s00376-016-5247-3.

,$- \ldots$, and L. Shaffrey, 2017: Understanding the rapid summer warming and changes in temperature extremes since the mid1990s over western Europe. Climate Dyn., 48, 1537-1554, https://doi.org/10.1007/s00382-016-3158-8.

Flanner, M. G., and C. S. Zender, 2005: Snowpack radiative heating: Influence on Tibetan Plateau climate. Geophys. Res. Lett., 32, L06501, https://doi.org/10.1029/2004GL022076.

Gao, Y. Q., and Coauthors, 2015: Arctic sea ice and Eurasian climate: A review. Adv. Atmos. Sci., 32, 92-114, https://doi.org/ 10.1007/s00376-014-0009-6.

Ge, Y., and G. Gong, 2009: North American snow depth and climate teleconnection patterns. J. Climate, 22, 217-233, https:// doi.org/10.1175/2008JCLI2124.1.

Groisman, P. Ya., T. R. Karl, R. W. Knight, and G. L. Stenchikov, 1994: Changes of snow cover, temperature, and radiative heat balance over the Northern Hemisphere. J. Climate, 7, 1633-1656, https://doi.org/10.1175/1520-0442(1994)007<1633: COSCTA $>2.0 . \mathrm{CO} ; 2$.

Halder, S., and P. A. Dirmeyer, 2017: Relation of Eurasian snow cover and Indian summer monsoon rainfall: Importance of the delayed hydrological effect. J. Climate, 30, 1273-1289, https:// doi.org/10.1175/JCLI-D-16-0033.1.

He, S. P., Y. Q. Gao, T. Furevik, H. J. Wang, and F. Li, 2018: Teleconnection between sea ice in the Barents Sea in June and the Silk Road, Pacific-Japan, and East Asian rainfall patterns in August. Adv. Atmos. Sci., 35, 52-64, https://doi.org/10.1007/ s00376-017-7029-y.

Heidinger, A. K., A. T. Evan, M. J. Foster, and A. Walther, 2012: A naive Bayesian cloud-detection scheme derived from CALIPSO and applied within PATMOS-x. J. Appl. Meteor. Climatol., 51, 1129-1144, https://doi.org/10.1175/JAMC-D-11-02.1.

Hirota, N., and M. Takahashi, 2012: A tripolar pattern as an internal mode of the East Asian summer monsoon. Climate Dyn., 39, 2219-2238, https://doi.org/10.1007/s00382-0121416-y.
Hong, X. W., and R. Y. Lu, 2016: The meridional displacement of the summer Asian jet, Silk Road pattern, and tropical SST anomalies. J. Climate, 29, 3753-3766, https://doi.org/10.1175/ JCLI-D-15-0541.1.

$\longrightarrow,-$, and S. L. Li, 2017: Amplified summer warming in Europe-West Asia and Northeast Asia after the mid-1990s. Environ. Res. Lett., 12, 094007, https://doi.org/10.1088/17489326/aa7909.

Hsu, H.-H., and S.-H. Lin, 1992: Global teleconnections in the 250mb streamfunction field during the Northern Hemisphere winter. Mon. Wea. Rev., 120, 1169-1190, https://doi.org/ 10.1175/1520-0493(1992)120<1169:GTITMS > 2.0.CO;2.

Ito, H., N. C. Johnson, and S. P. Xie, 2013: Subseasonal and interannual temperature variability in relation to extreme temperature occurrence over East Asia. J. Climate, 26, 9026-9042, https://doi.org/10.1175/JCLI-D-12-00676.1.

Iwao, K., and M. Takahashi, 2008: A precipitation seesaw mode between northeast Asia and Siberia in summer caused by Rossby waves over the Eurasian continent. J. Climate, 21, 2401-2419, https://doi.org/10.1175/2007JCLI1949.1.

Kalnay, E., and Coauthors, 1996: The NCEP/NCAR 40-Year Reanalysis Project. Bull. Amer. Meteor. Soc., 77, 437-472, https://oi.org/10.1175/1520-0477(1996)077<0437:TNYRP>2.0.CO;2.

Kamae, Y., and M. Watanabe, 2013: Tropospheric adjustment to increasing $\mathrm{CO}_{2}$ : Its timescale and the role of land-sea contrast. Climate Dyn., 41, 3007-3024, https://doi.org/10.1007/s00382012-1555-1.

—, H. Shiogama, M. Watanabe, and M. Kimoto, 2014: Attributing the increase in Northern Hemisphere hot summers since the late 20th century. Geophys. Res. Lett., 41, 51925199, https://doi.org/10.1002/2014GL061062.

Kosaka, Y., J. S. Chowdary, S. P. Xie, Y. M. Min, and J. Y. Lee, 2012: Limitations of seasonal predictability for summer climate over East Asia and the northwestern Pacific. J. Climate, 25, 7574-7589, https://doi.org/10.1175/JCLI-D-12-00009.1.

Koster, R. D., Y. H. Chang, H. L. Wang, and S. D. Schubert, 2016: Impacts of local soil moisture anomalies on the atmospheric circulation and on remote surface meteorological fields during boreal summer: A comprehensive analysis over North America. J. Climate, 29, 7345-7364, https://doi.org/10.1175/JCLI-D-160192.1.

Li, H. X., H. P. Chen, H. J. Wang, J. Q. Sun, and J. H. Ma, 2018: Can Barents sea ice decline in spring enhance summer hot drought events over northeastern China? J. Climate, 31, 4705-4725, https://doi.org/10.1175/JCLI-D-17-0429.1.

Lu, R. Y., J. H. Oh, and B. J. Kim, 2002: A teleconnection pattern in upper-level meridional wind over the North African and Eurasian continent in summer. Tellus, 54A, 44-55, https:// doi.org/10.3402/tellusa.v54i1.12122.

Matsumura, S., and K. Yamazaki, 2012: Eurasian subarctic summer climate in response to anomalous snow cover. J. Climate, $\mathbf{2 5}$, 1305-1317, https://doi.org/10.1175/2011JCLI4116.1.

Molotch, N. P., T. H. Painter, R. C. Bales, and J. Dozier, 2004: Incorporating remotely-sensed snow albedo into a spatiallydistributed snowmelt model. Geophys. Res. Lett., 31, L03501, https://doi.org/10.1029/2003GL019063.

$\mathrm{Mu}$, S. N., and G. Q. Zhou, 2010: Relationship between winter Northern Eurasian fresh snow extent and summer climate anomalies in China (in Chinese). Chin. J. Atmos. Sci., 34, 213-226. -, and _ 2012: Mechanism for the correlation of winter fresh snow extent over northern Eurasia and summer climate anomalies in China: Anomalous seasonal transition of land as a bond (in Chinese). Chin. J. Atmos. Sci., 36, 297-315. 
North, G. R., T. L. Bell, R. F. Cahalan, and F. J. Moeng, 1982: Sampling errors in the estimation of empirical orthogonal functions. Mon. Wea. Rev., 110, 699-706, https://doi.org/ 10.1175/1520-0493(1982)110<0699:SEITEO > 2.0.CO;2.

Orth, R., and S. I. Seneviratne, 2017: Variability of soil moisture and sea surface temperatures similarly important for warm-season land climate in the Community Earth System Model. J. Climate, 30, 2141-2162, https://doi.org/10.1175/JCLI-D-15-0567.1.

Rodell, M., and Coauthors, 2004: The Global Land Data Assimilation System. Bull. Amer. Meteor. Soc., 85, 381-394, https://doi.org/10.1175/BAMS-85-3-381.

Sato, T., and T. Nakamura, 2019: Intensification of hot Eurasian summers by climate change and land-atmosphere interactions. Sci. Rep., 9, 10866, https://doi.org/10.1038/s41598-01947291-5.

Schubert, S. D., H. L. Wang, and M. Suarez, 2011: Warm season subseasonal variability and climate extremes in the Northern Hemisphere: The role of stationary Rossby waves. J. Climate, 24, 4773-4792, https://doi.org/10.1175/JCLI-D-10-05035.1.

,-- R. D. Koster, M. J. Suarez, and P. Ya. Groisman, 2014: Northern Eurasian heat waves and droughts. J. Climate, 27, 3169-3207, https://doi.org/10.1175/JCLI-D-13-00360.1.

Seneviratne, S. I., T. Corti, E. L. Davin, M. Hirschi, E. B. Jaeger, I. Lehner, B. Orlowsky, and A. J. Teuling, 2010: Investigating soil moisture-climate interactions in a changing climate: A review. Earth-Sci. Rev., 99, 125-161, https://doi.org/10.1016/ j.earscirev.2010.02.004.

Shen, H. B., F. Li, S. P. He, Y. J. Orsolini, and J. Y. Li, 2020: Impact of late spring Siberian snow on summer rainfall in southcentral China. Climate Dyn., 54, 3803-3818, https://doi.org/ 10.1007/s00382-020-05206-5.

Shinoda, M., 2001: Climate memory of snow mass as soil moisture over central Eurasia. J. Geophys. Res., 106, 33 393-33 403, https://doi.org/10.1029/2001JD000525.

Souma, K., and Y. Q. Wang, 2010: A comparison between the effects of snow albedo and infiltration of melting water of Eurasian snow on East Asian summer monsoon rainfall. J. Geophys. Res., 115, D02115, https://doi.org/10.1029/ 2009JD012189.

Sun, C., R. Zhang, W. Li, J. Zhu, and S. Yang, 2019: Possible impact of North Atlantic warming on the decadal change in the dominant modes of winter Eurasian snow water equivalent during 1979-2015. Climate Dyn., 53, 5203-5213, https:// doi.org/10.1007/s00382-019-04853-7.

Sun, X. Q., S. L. Li, and B. Liu, 2019a: Comparative analysis of the mechanisms of intensified summer warming over EuropeWest Asia and Northeast Asia since the mid-1990s through a process-based decomposition method. Adv. Atmos. Sci., 36, 1340-1354, https://doi.org/10.1007/s00376-019-9053-6.

,,-- X. W. Hong, and R. Y. Lu, 2019b: Simulated influence of the Atlantic multidecadal oscillation on summer Eurasian nonuniform warming since the mid-1990s. Adv. Atmos. Sci., 36, 811-822, https://doi.org/10.1007/s00376-019-8169-z.

Sutton, R. T., B. W. Dong, and J. M. Gregory, 2007: Land/sea warming ratio in response to climate change: IPCC AR4 model results and comparison with observations. Geophys. Res. Lett., 34, L02701, https://doi.org/10.1029/2006GL028164.

Takala, M., K. Luojus, J. Pulliainen, C. Derksen, L. Lemmetyinen, J.-P. Kärnä, J. Koskinen, and B. Bojkov, 2011: Estimating Northern Hemisphere snow water equivalent for climate research through assimilation of space-borne radiometer data and ground-based measurements. Remote Sens. Environ., 115, 3517-3529, https://doi.org/10.1016/j.rse.2011.08.014.
Takaya, K., and H. Nakamura, 2001: A formulation of a phaseindependent wave-activity flux for stationary and migratory quasigeostrophic eddies on a zonally varying basic flow. J. Atmos. Sci., 58, 608-627, https://doi.org/10.1175/15200469(2001)058<0608:AFOAPI >2.0.CO;2.

Terao, T., 1998: Barotropic disturbances on intraseasonal time scales observed in the midlatitudes over the Eurasian continent during the northern summer. J. Meteor. Soc. Japan, 76, 419-436, https://doi.org/10.2151/jmsj1965.76.3_419.

Thompson, D. W. J., and J. M. Wallace, 2000: Annular modes in the extratropical circulation. Part I: Month-to-month variability. J. Climate, 13, 1000-1016, https://doi.org/10.1175/1520-0442(2000) 013<1000:AMITEC > 2.0.CO;2.

Wang, S., D. Nath, W. Chen, and L. Wang, 2019: Recent strengthening of Greenland blocking drives summertime surface warming over northern Canada and eastern Siberia. J. Climate, 32, 3263-3278, https://doi.org/10.1175/JCLI-D-18-0410.1.

Wu, B. Y., K. Yang, and R. H. Zhang, 2009: Eurasian snow cover variability and its association with summer rainfall in China. Adv. Atmos. Sci., 26, 31-44, https://doi.org/10.1007/s00376009-0031-2.

Wu, R. G., and B. P. Kirtman, 2007: Observed relationship of spring and summer East Asian rainfall with winter and spring Eurasian snow. J. Climate, 20, 1285-1304, https://doi.org/ 10.1175/JCLI4068.1.

- , and S. F. Chen, 2016: Regional change in snow water equivalent-surface air temperature relationship over Eurasia during boreal spring. Climate Dyn., 47, 2425-2442, https:// doi.org/10.1007/s00382-015-2972-8.

_- G. Liu, and Z. Ping, 2014a: Contrasting Eurasian spring and summer climate anomalies associated with western and eastern Eurasian spring snow cover changes. J. Geophys. Res. Atmos., 119, 7410-7424, https://doi.org/10.1002/2014JD021764.

— P. Zhao, and G. Liu, 2014b: Change in the contribution of spring snow cover and remote oceans to summer air temperature anomaly over Northeast China around 1990. J. Geophys. Res. Atmos., 119, 663-676, https://doi.org/10.1002/2013JD020900.

Wu, Z. W., P. Zhang, H. Chen, and Y. Li, 2016: Can the Tibetan Plateau snow cover influence the interannual variations of Eurasian heat wave frequency? Climate Dyn., 46, 3405-3417, https://doi.org/10.1007/s00382-015-2775-y.

Xie, S.-P., H. Noguchi, and S. Matsumura, 1999: A hemisphericscale quasi-decadal oscillation and its signature in northern Japan. J. Meteor. Soc. Japan, 77, 573-582, https://doi.org/ 10.2151/jmsj1965.77.2_573.

Xu, B., H. S. Chen, S. L. Sun, and C. J. Gao, 2019: Large discrepancy between measured and remotely sensed snow water equivalent in the northern Europe and western Siberia during boreal winter. Theor. Appl. Climatol., 137, 133-140, https:// doi.org/10.1007/s00704-018-2580-8.

—, H. Chen, C. Gao, G. Zeng, and Q. Huang, 2021: Abnormal change in spring snowmelt over Eurasia and its linkage to East Asian summer monsoon: The hydrological effect of snow cover. Front. Earth Sci., 8, 594546, https://doi.org/10.3389/ FEART.2020.594656.

Xu, K., J. H. He, and C. W. Zhu, 2011: The interdecadal linkage of the summer precipitation in eastern China with the surface air temperature over Lake Baikal in the past 50 years (in Chinese). Acta Meteor. Sin., 69, 570-580.

$\mathrm{Xu}$, L., and P. Dirmeyer, 2011: Snow-atmosphere coupling strength in a global atmospheric model. Geophys. Res. Lett., 38, L13401, https://doi.org/10.1029/2011GL048049. 
and - , 2013: Snow-atmosphere coupling strength. Part II: Albedo effect versus hydrological effect. J. Hydrometeor., 14, 404-418, https://doi.org/10.1175/JHM-D-11-0103.1.

Xu, P. Q., L. Wang, and W. Chen, 2019: The British-Baikal corridor: A teleconnection pattern along the summertime polar front jet over Eurasia. J. Climate, 32, 877-896, https://doi.org/ 10.1175/JCLI-D-18-0343.1.

Xu, X. P., S. P. He, F. Li, and H. J. Wang, 2018: Impact of northern Eurasian snow cover in autumn on the warm Arctic-cold Eurasia pattern during the following January and its linkage to stationary planetary waves. Climate Dyn., 50, 1993-2006, https://doi.org/10.1007/s00382-017-3732-8.

Yao, J. X., X. Sun, J. Tang, Y. Ji, Y. Xu, and X.-Q. Yang, 2020: Summer regional pentad heat wave in eastern China and their possible causes. Front. Earth Sci., 8, 598027, https://doi.org/ 10.3389/feart.2020.598027.

Yasunari, T., A. Kitoh, and T. Tokioka, 1991: Local and remote responses to excessive snow mass over Eurasia appearing in the northern spring and summer climate. J. Meteor. Soc. Japan, 69, 473-487, https://doi.org/10.2151/jmsj1965.69.4_473.

Ye, K. H., and N. C. Lau, 2019: Characteristics of Eurasian snowmelt and its impacts on the land surface and surface climate. Climate Dyn., 52, 1115-1138, https://doi.org/10.1007/s00382018-4180-9.

— , R. G. Wu, and Y. Liu, 2015: Interdecadal change of Eurasian snow, surface temperature, and atmospheric circulation in the late 1980s. J. Geophys. Res. Atmos., 120, 2738-2753, https:// doi.org/10.1002/2015JD023148.

Yim, S. Y., J. G. Jhun, R. Y. Lu, and B. Wang, 2010: Two distinct patterns of spring Eurasian snow cover anomaly and their impacts on the East Asian summer monsoon. J. Geophys. Res., 115, D22113, https://doi.org/10.1029/2010JD013996.

Zhang, R. H., B. Y. Wu, P. Zhao, and J. P. Han, 2008: The decadal shift of the summer climate in the late 1980s over East China and its possible causes (in Chinese). Acta Meteor. Sin., 66, 697-706.

Zhang, R. N., R. H. Zhang, and Z. Y. Zuo, 2017: Impact of Eurasian spring snow decrement on East Asian summer precipitation. J. Climate, 30, 3421-3437, https://doi.org/10.1175/ JCLI-D-16-0214.1.

Zhao, P., Z. J. Zhou, and J. P. Liu, 2007: Variability of Tibetan spring snow and its associations with the hemispheric extratropical circulation and East Asian summer monsoon rainfall: An observational investigation. J. Climate, 20, 3942-3955, https://doi.org/10.1175/JCLI4205.1.

Zhu, C. W., B. Wang, W. H. Qian, and B. Zhang, 2012: Recent weakening of northern East Asian summer monsoon: A possible response to global warming. Geophys. Res. Lett., 39, L09701, https://doi.org/10.1029/2012GL051155.

Zuo, Z. Y., S. Yang, W. Q. Wang, A. Kumar, Y. Xue, and R. H. Zhang, 2011: Relationship between anomalies of Eurasian snow and southern China rainfall in winter. Environ. Res. Lett., 6, 045402, https://doi.org/10.1088/1748-9326/6/4/045402.

—, R. H. Zhang, B. Y. Wu, and X. Y. Rong, 2012: Decadal variability in springtime snow over Eurasia: Relation with circulation and possible influence on springtime rainfall over China. Int. J. Climatol., 32, 1336-1345, https://doi.org/10.1002/ joc.2355. 